\title{
The Pivotal Mechanism and Organizational Control
}

\author{
Yair Listokin*
}

\begin{abstract}
Organizations with multiple individuals typically make decisions by following the will of the majority of some subset of stakeholders that are entitled to vote. This paper examines an alternative decision-making mechanism - the "pivotal" mechanism developed by Groves and Clarke. Unlike voting, the pivotal mechanism produces efficient outcomes in the presence of heterogeneous voter preferences. Moreover, the mechanism allows control rights to be allocated more widely, reducing the costs of opportunism when a controlling class of stakeholders has interests adverse to another class. These benefits come with costs. The pivotal mechanism's efficiency diminishes in the presence of collusion between voters and requires the creation of "pools" that disperse revenues created by the mechanism. The mechanism is therefore most attractive when the costs of heterogeneity are large and the risks of collusion are small. As a result, I propose the development of a legal basis for the pivotal mechanism as a menu option for organizational decision making.
\end{abstract}

\footnotetext{
* Associate Professor of Law, Yale Law School. This Article benefited from extremely helpful comments by Ian Ayres, Robert Daines, Paul Edelman, William Rinner, Roberta Romano, Randall Thomas and seminar participants at Columbia Law School, University of Toronto Law School, and Vanderbilt Law School. All errors are my own.
} 


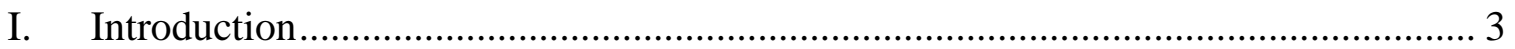

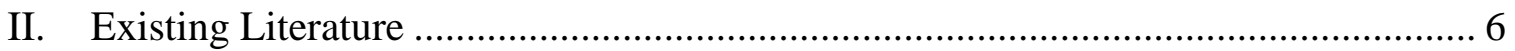

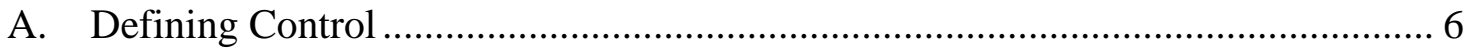

B. Minimizing Transaction Costs in an Organization through Control and Contract. 6

1. Contracting Costs ........................................................................................ 6

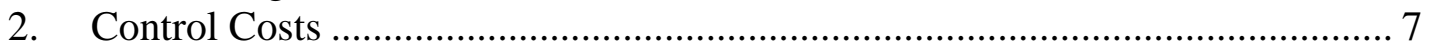

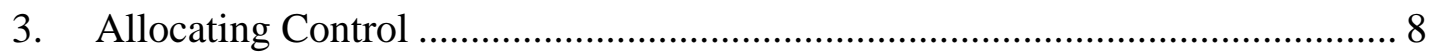

C. Critiques of This Framework ............................................................................. 11

1. Existing Arguments ....................................................................................... 11

2. Alternative Organizational Forms.................................................................. 12

3. The Direct and Indirect Costs of Majority Voting in the Presence of

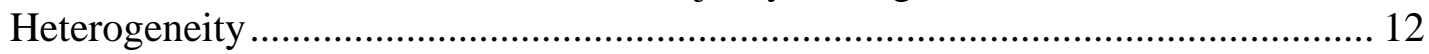

4. Other Means of Collective Decision Making ………......................................... 13

III. The VCG "Pivotal” Mechanism ........................................................................ 14

A. The Mechanism in Operation........................................................................... 14

B. Advantages of the Pivotal Mechanism ................................................................. 16

1. Efficient Outcomes in the Presence of Intense Preferences............................... 17

2. The Pivotal Mechanism Can Account for Other Stakeholders........................... 18

3. The Pivotal Mechanism and Decisional Incoherence......................................... 19

4. Curing the Ills of Preference Heterogeneity and Majority Voting: The Pivotal

Mechanism Versus Other Solutions........................................................................ 19

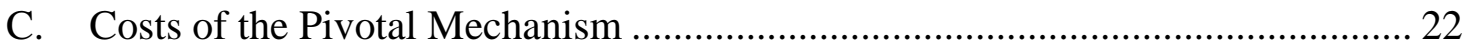

1. Direct Costs of the Pivotal Mechanism .......................................................... 23

2. Problems of Agenda Control ........................................................................ 25

3. Incentives for Truth Telling and Coalitions.................................................. 26

4. Determining Eligible Participants in the Mechanism ........................................ 27

5. Income and Wealth Limitations...................................................................... 29

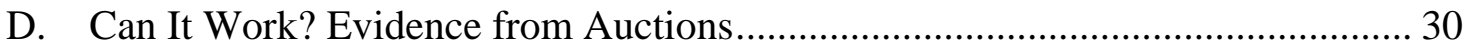

IV. Applications and Extensions.......................................................................... 31

A. Close Corporations and Partnerships.................................................................... 31

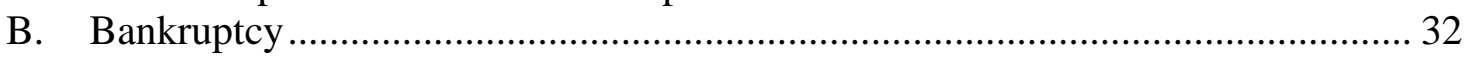

C. Other Applications of the Pivotal Mechanism....................................................... 34

1. Publicly Traded Corporations ........................................................................ 35

2. Non Profit Organizations ………………………....................................... 36

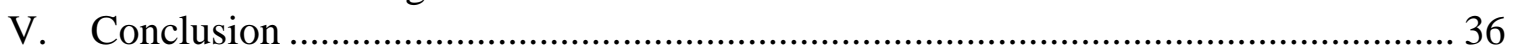




\section{Introduction}

In large organizations, who makes the decisions and how do they do so? Much of organizational law is preoccupied with these questions. Generally, decision-making is bifurcated. "Agents" of the organization make most decisions, but some other single class of "stakeholders", e.g. claimants to residual profits, ${ }^{1}$ alumni, ${ }^{2}$ or suppliers, ${ }^{3}$ often exercises control over critical decisions, such as the hiring or firing of the agents. This class of stakeholders exercises control through some form of voting.

While voting has many virtues as a control mechanism, it also has many flaws. Voting cannot measure intensity of preferences. ${ }^{4}$ If someone cares greatly about an issue but holds one vote, then that individual's preference is accorded no greater weight than another individual with a different preference but much less intensity. This makes the choice of a voting population critical. If a voting population for an organization is comprised of many individuals who care little about the organization, then these individuals may swing the vote in the direction of their slight preference, in spite of the fact that individuals with extremely strong preferences desire an alternative direction.

For-profit business corporations mitigate these flaws of voting by implementing control via majority or plurality voting by some claimants of residual profits. Requiring voting by residual claimants has the advantages of clearly defining the voting population and allocating control to a group with homogeneous preferences for maximizing profits.

Voting by residual claimants also entails some inefficiencies, however. The control rights associated with voting are valuable to many parties other than claimants to residual profits. Furthermore, residual claimants to some organizations, such as joint ventures or partnerships, transact with the organization not only as residual claimants but also as suppliers, customers, or employees. In these situations and others, patrons ${ }^{5}$ may purchase shares and exercise the concomitant voting power to maximize their total interest rather than their interest as residual claimants exclusively. In other words, ensuring homogeneity of preferences among shareholders is tricky and expensive. Thus, organizational law restricts "minority oppression", 6 "coercive tender offers", 7 "vote buying”, and "empty voting," in which control rights are exercised to maximize interests other than organization profit maximization. These restrictions are difficult to maintain,

\footnotetext{
${ }^{1}$ In a for profit corporation.

${ }^{2}$ A university.

${ }^{3}$ In a farm cooperative.

${ }^{4}$ For a discussion of vote buying and selling as a solution to the inability of voting to measure intensity of preferences, see Saul Levmore, Voting with Intensity, 53 Stan. L. Rev. 111 (2000).

${ }^{5}$ I use the terms "patron" and "stakeholder" interchangeably to refer to any party that interacts with an organization.

${ }^{6}$ See, e.g., Douglas K. Moll, Minority Oppression \& the Limited Liability Company: Learning (or Not) from Close Corporation History ," 40 Wake Forest Law Review 883 (2005).

${ }^{7}$ Frank Easterbrook \& Daniel R. Fischel. “The Proper Role of a Target’s Management in Responding to a Tender Offer.”94 Harvard Law Review 1161 (1981); Jonathan R. Macey \& Fred S. McChesney. “A Theoretical Analysis of Corporate Greenmail.” Yale Law Journal 95 (1985): 113.

${ }^{8}$ See Robert B. Thompson \& Paul H. Edelman, Corporate Voting, 62 Vand. L. Rev. 129, 131 (2009) (discussing empty voting).
} 
however, and many academics now decry the existence of empty voting, ${ }^{9}$ in which voting rights are decoupled from claims on residual profits through the use of derivatives.

Even if all votes are cast with the intention of maximizing residual profits, voting exclusively by shareholders causes other inefficiencies. For example, the "asset substitution" problem encourages corporations controlled by claimants to residual profits to take inefficient risks, since the upside of the risks are enjoyed by the residual claimants while the downsides are shared with the creditor class of patrons. ${ }^{10}$ Similarly, some inefficient changes in corporate control may take place because control is vested with residual claimants to profits, who may ignore the surplus enjoyed by employees that will be destroyed by a change in control. ${ }^{11}$ In both cases, the inability of voting to account for the interests of stakeholders other than residual claimants causes inefficiencies. To reduce these costs, other stakeholders may desire some measure of control of the corporation. Under current law, however, obtaining such control requires the concomitant acquisition of a right to residual profits. Because of risk aversion or capital constraints, stakeholders may view the costs of buying a dual right to control and residual profits prohibitive, even if a simple right to control is worth acquiring.

Voting as a control mechanism performs proves problematic for non profit organizations as well as for profits. ${ }^{12}$ Non-profit organizations ${ }^{13}$ have no obvious analogue to residual claimants as a relatively homogenous group of patrons able to exercise control. In spite of this heterogeneity, most non profit organizations-just like for profit corporations-- rely on voting to aggregate preferences. Condominium organizations, for example, rely on majority voting to make important decisions, making it no surprise that condominium decisions are frequently fraught with strife. ${ }^{14}$

Voting is only one technology for exercising control, however. Therefore, these costs associated with voting are not inescapable. To mitigate the costs imposed by voting, I propose that organizational law should develop and allow the Vickrey Clarke Groves ("VCG”) "pivotal” decision making mechanism as an alternative to voting. ${ }^{15}$ The pivotal mechanism, developed by public choice scholars in the 1970s and currently unmentioned by organizational law, addresses many of the critiques of voting just presented, but introduces a different set of costs. As a result, I believe that organizational law should enable the VCG mechanism as an option for organizations and allow them to choose their preferred decision making mechanism.

\footnotetext{
${ }^{9}$ Black \& Hu, http://papers.ssrn.com/sol3/papers.cfm?abstract_id=904004; Edelman \& Thompson, http://papers.ssrn.com/sol3/papers.cfm?abstract_id=1156901.

${ }^{10}$ Michael Jensen \& William H. Meckling, "Theory of the Firm: Managerial Behavior, Agency Costs and Ownership Structure” (1976) 3 J. Fin. Econ. 305. Jochen Bigus, Bankruptcy Law, Asset Substitution Problem, and Creditor Conflicts, 22 Int'l Rev. L. \& Econ. 109, 128 (2002); Note, 86 Tex. L. Rev. 857, 873 (discussing asset substitution)

${ }^{11}$ See Andrei Shleifer \& Lawrence H. Summers, "Breach of Trust in Hostile Takeovers”, in Corporate Takeovers: Causes and Consequences 33, 37-41 (Alan J. Auerbach ed., 1988)).

${ }^{12}$ An important exception is state, local, and national governments, which are large not for profit organizations that rely on voting by citizens for decision-making.

13 Such organizations produce over $7 \%$ of GDP.

http://www.jhu.edu/ccss/publications/pdf/Measuring_Civil_Society.pdf

14 See, e.g., http://www.ccfj.net/HOAgencondocomm.html (discussing condominium board strife). McKenzie, Evan. Privatopia: Homeowner Associations and the Rise of Residential Private Governments.

${ }^{15}$ See Edward Clarke, Multipart Pricing of Public Goods, 11 Public Choice 17 (1971); Theodore Groves, Incentives in Teams, 41 Econometrica 617 (1973).
} 
To illustrate how the mechanism functions, consider a condominium organization's decision between two sets of amenities (Basic and Lavish). Basic prescribes spartan common amenities, while Lavish prescribes lavish amenities). The condominium complex has three condominium unit owners ("stakeholders")—Emerson, Trump , and Thoreau. Each stakeholder has potentially different preferences for Basic and Lavish. A state official asks each stakeholder their relative valuation of Basic versus Lavish (these values can be positive or negative). The relative valuation reflects how much better off - in dollar terms - each owner is with Basic relative to Lavish. If Thoreau, for example, views the costs of Lavish as greater than the benefits of nicer amenities, then Thoreau will have a positive relative valuation for Basic. ${ }^{16}$ The official then adds up each stakeholder's relative valuation report. If the total valuation of Basic is positive, then decision Basic is taken. Otherwise decision Lavish is taken. If any of Emerson, Trump , and C's preferences is pivotal (cause the decision between Basic and Lavish to change, (e.g. if the sum of Trump and Thoreau is negative, but the sum of Emerson, Trump , and Thoreau is positive, then Emerson is pivotal), then the stakeholder with the pivotal preferences must pay the negative of the sum of Trump and Thoreau into a pool. Trump and Thoreau pay nothing into the pool because they are not pivotal. The money in the pool goes to the state or some other group of claimants on the pool. ${ }^{17}$

Economic theory demonstrates that the mechanism induces "truth telling" by stakeholders. That is, each stakeholder has an incentive to state their true valuation of Basic relative to Lavish. Moreover, it can be shown that decision Basic will be taken only if the combined value assigned to decision Basic is greater than the combined value assigned to decision Lavish, which means that the decision is efficient from a KaldorHicks perspective. This is not the case with ordinary voting. Finally the pivotal mechanism dispenses with the need to define the set of patrons with the right to vote. ${ }^{18}$ Instead, anyone can vote. The pivotal mechanism thereby addresses many of the problems associated with voting, such as heterogeneity of shareholder preference intensity, asset substitution, violation of implicit contracts, and defining the voting populations. The mechanism will be most attractive for organizations wherein these costs are most salient.

Consequently, I propose that organizational law be modified to enable the use of the pivotal mechanism for important organizational decisions. The ability to participate in the VCG mechanism could be limited to individuals in a certain group, such as owners of condominium units, or it could extended to anyone identifying as a stakeholder (such as condominium doorpersons), with the proviso that each participant must pay into the pool if they become the pivotal voter. After the VCG decision is taken, any surplus funds produced by the mechanism are allocated to a pool of other organizations that make decisions by the pivotal mechanism. ${ }^{19}$

The Article proceeds as follows. Section II examines current theories and current theories of organizational control and demonstrates how voting technology occupies a

\footnotetext{
${ }^{16}$ If fancy amenities are worth more to Thoreau than their costs, then Thoreau will have a positive valuation for Lavish.

${ }^{17}$ The distribution of the pool of money will be discussed below.

${ }^{18}$ Alternatively, the VCG mechanism could limit participation to some subgroup of stakeholders. Under some assumptions, discussed below, this will be less efficient, but it also offers the possibility of reducing cost.

${ }^{19}$ The mechanics of the pool are discussed in greater detail below.
} 
central place in these theories. Section III then develops an the VCG pivotal mechanism as an alternative decision making mechanism to voting and discusses the salient costs and benefits of the pivotal mechanism.

\section{Existing Literature}

\section{A. Defining Control}

From an economic perspective, organizations are a "nexus of contracts" with a wide variety of "patrons”, including employees, suppliers of capital, and customers. ${ }^{20}$ These contracts articulate the rights and obligations of all patrons with respect to the corporation. Inevitably, however, each contract contains gaps. Legal rules and standards, such as fiduciary duties or principles of contractual interpretation, seek to fill these gaps, ${ }^{21}$ but these rules are imperfect and costly to enforce. Thus, there must be some mechanism for making decisions that are not stipulated by contract. The right to participate in this mechanism is called "control".

\section{B. Minimizing Transaction Costs in an Organization through Control and Contract}

Hansmann explains that organizations can transact with patrons of a firm in one of two ways - contract or control. In a contractual relationship, a patron is guaranteed its contractual rights, but no more. In a control position, by contrast, a patron enjoys the ability to exploit contractual gaps in its favor. If there are no transaction costs associated with either contract or control, then the allocation of authority is irrelevant. Bargaining between the parties will insure efficient transacting regardless of organizational Once we assume the existence of costs, however, the allocation of contract and control assumes importance. The costs associated with transacting via contracting relative to control are examined therefore examined here.

\section{Contracting Costs}

Contracting costs include problems of monopoly, “lock-in”, and asymmetric information. ${ }^{22}$ Each of these factors prevents efficient transactions from occurring. Monopoly inefficiencies occur when a monopolist imposes a price above marginal cost, ensuring that some efficient transactions will not take place. Lock-in arises when one party, such as an employee, must make a substantial investment in an asset that is specific to the other party. ${ }^{23}$ Some costly but efficient investment may not occur in such cases because the party that makes the investment will not recoup the investment cost as the

\footnotetext{
${ }^{20}$ Stephen M. Bainbridge, Corporation Law and Economics 27 (2002); Frank Easterbrook \& Daniel Fischel, "Voting in Corporate Law, Journal of Law and Economics 401 (1983).

${ }^{21}$ Jonathan R. Macey, Fiduciary Duties as Residual Claims: Obligations to Nonshareholder Constituencies from a Theory of the Firm Perspective, 84 CORNELL L. REV. 1266, 1273 (1999) (characterizing fiduciary duty as a "gap-filling" mechanism for unspecified contractual terms).

${ }^{22}$ Henry Hansmann, The Ownership of Enterprise 24-34 (1996).

${ }^{23}$ Farrell \& Shapiro, Optimal Contracts with Lock-in, 1989 American Econ. Rev.
} 
other party takes advantage of the fact that the investment is locked in. For example, employees may avoid undertaking efficient but costly investments on training that is unique to their firm because, after they make the investment, the firm may not raise their wages, knowing that the training is worthless with any other firm. Asymmetric information costs arise when one party to a transaction has greater information than another party, potentially preventing efficient transactions from occurring because the party with poorer information suspects it will be taken advantage of. ${ }^{24}$

Control reduces these costs. For example, if the customers of a monopoly control the monopolist, then the monopolist will not charge prices that allow it to obtain rents, thereby eliminating the deadweight loss associated with monopoly. Hansmann argues that when contracting costs are high for a class of patrons, then that class of patrons is more likely to be granted control, ceteris paribus

\section{Control Costs}

Granting control rights to a class of patrons also entails costs. These costs include the opportunism that arises when a controlling patron's incentives conflict with the organization's interests and the costs of collective decision making ${ }^{25}$.

\section{a) Costs of Opportunism}

With control, patrons can take inefficient actions that benefit themselves but impose greater costs on other patrons. A well known example of opportunism is the "asset substitution" problem, where residual claimants take inefficient risks because they enjoy all of the upside benefits but share the costs of failure with creditors and other claimants. ${ }^{26}$ Another instance of opportunism occurs when those controlling an organization breach implicit contracts, which are not legally enforceable. ${ }^{27}$ For example, organizations may induce effort and investment in younger employees by promising above market wages in later years as a reward for good performance. Good performance may be unverifiable, however, so the agreement cannot be reduced to contract. As a result, the controlling patrons can have the organization renege on the implicit contract if it suits the controlling patrons' interest. Knowing this, younger workers may fail to incur efficient levels of effort and investment, fearing that such investment will not be rewarded at a later date as provided by the implicit contract. ${ }^{28}$

Non profit organizations can also exercise control opportunistically. When a non profit organization issues debt, it will have similar incentives to opportunistically dilute the value of the debt by taking risks as for profit organizations. ${ }^{29}$ The leaders of an organization, for example, may use funds to build impressive buildings that raise the probability of insolvency. The costs of insolvency fall in part upon lenders, while the

\footnotetext{
${ }^{24}$ David de Meza \& David C. Webb, Too Much Information: A Problem of Asymmetric Information.

${ }^{25}$ Hansmann, supra note 22 Chapter 3.

${ }^{26}$ See Mark Grinblatt \& Sheridan Titman, Financial Markets and Corporate Strategy 569-75 (2002).

${ }^{27}$ Clive Bull, Implicit Contracts in the Absence of Enforcement and Risk Aversion, 73 Am. Econ. Rev. 658 (1983).

${ }^{28}$ Lisa M. Lynch, Private-Sector Training and the Earnings of Young Workers, 82 Am. Econ. Rev. 299 (1992).

${ }^{29}$ Patrick Bolton \& David S. Scharfstein, Optimal Debt Structure and the Number of Creditors, 104 J. Pol. Econ.
} 
benefits of impressive buildings_-e.g. potentially attracting members and providing comfort to existing users—are not enjoyed by the creditors.

\section{b) Costs of Collective Action and Voting}

Control rights mean nothing if they cannot be exercised. The class of patrons with control must have some method of taking collective action. In practice, corporate law and commentators assume that voting is the only means of collective decision making. ${ }^{30}$ While corporate charters may specify the "votes that shall be necessary for the transaction of any business", there is no indication that a corporation is free to eliminate voting entirely. Majority voting is the default rule for most corporate decisions that must be made by vote, while plurality voting is the default rule for director elections. ${ }^{31}$ Delaware corporate law also explicitly recognizes the possibility of cumulative voting for directors. ${ }^{32}$ Similarly, academic commentary on the allocation of power in organizations focuses exclusively on "voting schemes" rather than other collective choice mechanisms. ${ }^{33}$

Voting imposes several transactional inefficiencies. First, voting is expensive and time consuming, requiring many disparate parties to obtain knowledge about the problem at hand and make the effort to vote. In large voting pools, individual voters have a small probability of changing the outcome, and therefore may rationally remain uninformed; diminishing the chance that voting produces a collective decision that is actually supported by the voting population. Second, voting produces inefficient decisions in many cases where the set of controlling patrons exhibit diverse preferences. Majority voting, for example, favors the choice of the median voter, while efficiency aims to maximize value for the average voter. These inefficient decisions occur when a small group of controllers desire some action intensely but are outvoted by a larger group that mildly dislikes some action. In these circumstances, a vote on an action may lose in spite of the fact that those who desire the action would be willing to pay more for the action than those against would accept. ${ }^{34}$

\section{Allocating Control}

Each group of patrons has differing costs of transacting with the organization via contract or control. Easterbrook and Fischel and Hansmann argue that control is allocated to minimize the total costs of patrons transacting with the organization.

\footnotetext{
${ }^{30}$ See 8 Del Code 216. speaking of "the vote that shall be required for a certain action". Proportional voting is also presumed to occur in non stock corporations, See 8 Del Code 215, and in Professional Corporations, 8 Del. Code 612.

${ }^{31} 8$ Del. Code 216(2), 216(3).

328 Del. Code 214. The explicit authorization of cumulative voting but not other voting mechanisms may imply that other complicated forms of voting, such as the Hare system, Coombs system, or Borda count see Mueller, 147-48, are forbidden.

${ }^{33}$ Hanmann, at 39

${ }^{34}$ While the inefficiencies associated with opportunism arise because the controlling class of patrons take actions that harm other classes of patrons more than they benefit the controlling class, the inefficiencies associated with voting imply that decisions that impose a net loss on the controlling class of patrons alone may be taken. See Rafael La Porta, Florencio Lopez-de-Silanes \& Andrei Schleifer, Corporate Ownership Around the World, 54 J. Fin. 471 (1999).
} 
In a typical large organization, the vast majority of control rights are exercised by patrons of the organization termed the board of directors ("management”). ${ }^{35}$ Granting control rights to management allows decisions to be made relatively quickly and cheaply. Requiring a vote for all organizational decisions is not feasible.

Management control, however, raises the specter of principal agent problems. Instead of running the organization to maximize its benefit for all patrons, management may run the organization to maximize the benefit to itself. Fiduciary duties may limit managerial opportunism, but cannot eliminate it. As a result, management generally does not have unfettered control over the organization. Instead, some class of patrons generally exercises control on important issues such as the choice of management.

Hansmann $^{36}$ and Easterbrook and Fischel ${ }^{37}$ assume that control should only be exercised by one group of patrons. They observe that heterogeneity of preferences, which is likely to be extreme when multiple groups of patrons enjoy voting rights, raises the probability that median preferences diverge from average preferences, leading to inefficient voting choices. Heterogeneity of preferences also causes other voting pathologies, such as the possibility of inconsistent choices based on vote ordering. The Condorcet paradox for example, demonstrates that majority voting may enable a choice A to beat choice $B$ and choice $B$ to beat choice $C$, but choice $C$ may still defeat A. Thus, the choice between $\mathrm{A}, \mathrm{B}$, and $\mathrm{C}$ under majority voting depends upon the order in which different choices are voted upon. ${ }^{38}$

Which class of patrons should exercise this element of control over management? Easterbrook and Fischel observe that "voting rights are universally held by shareholders, to the exclusion of bondholders, managers, and other employees.” While this observation does not apply to non profit organizations, mutually owned corporations, or cooperatives, it accurately describes most publicly held for profit corporations. They explain that "residual claimants ... are the group with the appropriate incentives to make discretionary decisions" because they receive "most of the marginal gains and incur most of the marginal costs" of decision making. ${ }^{39}$ Moreover, Easterbrook and Fischel argue that when voters hold dissimilar preferences it is not possible to aggregate their preferences into a consistent system of choices [due to Arrow's impossibility theorem]. If a firm makes inconsistent choices, it is likely to self-destruct. Consistency is possible, however, when voters commonly hold the same ranking of choices (or when the rankings are at least single-peaked). ${ }^{40}$

\footnotetext{
${ }^{35}$ In turn, management delegates control to many other employees. Indeed, all employees exert some level of control over their labor and the other assets of the organization. See Barry D. Baysinger \& Henry N. Butler, Corporate Governance and the Board of Directors: Performance Effects of Changes in Board Composition, 1 J.L. Econ. \& Org. 101 (1985).

${ }^{36}$ Hansmann at 62-64.

${ }^{37}$ Easterbrook and Fischel at 405,

${ }^{38}$ See Kenneth J. Arrow, A Difficulty in the Concept of Social Welfare, 58 J. Pol. Econ. 328 (1954); Grant Hayden \& Mathew Bodie, Arrow's Theorem and the Exclusive Shareholder Franchise, 62 Vand. L. Rev. (2009).

39 This claim is debatable. Employees may also bear a significant amount of marginal costs and benefits or decision-making, to say nothing of customers, local residents etc.. Even the government, through corporate taxation, receives a substantial share of the benefits of profitable new projects.

${ }^{40}$ Easterbrook \& Fischel at 405.
} 
Because allocation of voting rights to shareholders internalizes most residual claims while preventing Arrow theorem related decision cycling, Easterbrook and Fischel argue that this allocation is efficient.

Hansmann emphasizes another benefit of the residual claimants shared goal in maximizing residual profits. ${ }^{41}$ Shared goals reduces heterogeneity, which in turn reduces the possibility that voting produces inefficient outcomes. The inefficient outcomes are not simply a product of Arrow related cycling, but are rather due to the inefficiency of majority voting in the presence of differing preference intensities. ${ }^{42}$ Employees, by contrast, "are far more likely than investors to differ among themselves concerning the firm's policies." 43 As a result, employee control is relatively rare, in spite of the large costs associated with acquiring labor via market contracting. ${ }^{44}$

These arguments also explain why voting rules are presumptively one share of residual profits per vote. Other allocations of voting power, such as dual share classes with different voting powers, raise the possibility that a patron can obtain power and cease maximizing residual profits without having to pay the full cost of lost profits, thereby leading to inefficiencies. ${ }^{45}$

Hansmann expands the framework of transaction cost minimization to explain other patterns of control. In some cases, a class of patrons will have high transaction costs of both ownership and contracting. Long term apartment rentals, for example, entail considerable risks. ${ }^{46}$ The tenant may not adequately invest in items which will pay off after the tenant has left. The landlord may hold up the tenant when the lease is up and charge a high rent, knowing that it is costly for the tenant to move. ${ }^{47}$ Consequently, many apartment buildings are not owned by tenants, but rather in cooperative or condominium form. These forms also entail costs, most prominently the costs of collective decision making when joint owners have heterogeneous preferences. Hansmann presents the example of joint owners in cooperatives or condominiums disagreeing about the quality of the fixtures leading to "outcomes that fail to maximize the aggregate welfare of the occupants". 48

Insurance policyholders, for example, write long term contracts with an insurance company. ${ }^{49}$ Such long term contracts are inevitably incomplete and involve considerable risk. Having the insured own the firm, however, also involves significant risks, as the insured will not be able to monitor management entrusted with day to day decisionmaking. Nevertheless, many insurance companies are mutually controlled. ${ }^{50}$ Although the insured cannot monitor management effectively, mutual ownership guarantees that

\footnotetext{
${ }^{41}$ Hansmann at 62-63.

${ }^{42}$ Eyal Baharad \& Shmuel Nitzan, Ameliorating Majority Decisiveness Through Expression of Preference Intensity, 96 Am. Pol. Sci. Rev. 745 (2002).

${ }^{43}$ Hansmann at 89-90.

${ }^{44}$ See Hansmann chapter 5.

${ }^{45}$ See, e.g., Oliver Hart, Firms, Contracts, and Financial Structure 186-191 (1995).

${ }^{46}$ Todd Sinai \& Nicholas S. Souleles, Owner-Occupied Housing as a Hedge Against Rent Risk, 120 Q.J. Econ. 763 (2005).

${ }^{47}$ Hansmann at 200.

${ }^{48}$ Hansmann 200-201.

${ }^{49}$ Michael C. Keeley, Deposit Insurance, Risk, and Market Power in Banking, 80 Am. Econ. Rev. 1183 (1990).

${ }^{50}$ David Mayers \& Clifford W. Smith, Jr., Contractual Provisions, Organizational Structure, and Conflict Control in Insurance Markets, 54 J. Bus. 407 (1981).
} 
management is not beholden to other interests. In extreme cases where both market contracting and ownership are extraordinarily expensive, organizations may become nonprofits with all control vested in self-perpetuating management. While this entails obvious principal agent costs, these costs may be lower than assigning control to any other class of patrons. ${ }^{51}$

\section{Critiques of This Framework}

The existing framework provides a convincing explanation for many patterns of control. Nevertheless, the framework makes several questionable assumptions. If these assumptions prove false, the framework's explanatory power and normative force are greatly attenuated.

\section{Existing Arguments}

Many scholars have critiqued the "transaction cost” framework's explanation for control patterns of publicly traded for profit corporations.

Scholars have critiqued many of the assumptions underlying the Easterbrook and Fischel argument for an exclusive shareholder franchise. Blair argues that shareholders are not the only residual claimants, pointing out that employees and customers can also be residual claimants of a corporate decision. ${ }^{52}$ This echoes the argument by Summers and Shliefer that employees have implied contractual claims on a firm that are expropriated by shareholders in takeovers. ${ }^{53}$ In a recent article, Hayden and Bodie take aim at Easterbrook and Fischel's argument that voter heterogeneity caused by allowing voting by disparate stakeholders leads to incoherent outcomes. ${ }^{54}$ Hayden and Bodie note that shareholders are themselves often heterogeneous, and that all Arrow's impossibility theorem demonstrates that all collective choice mechanisms entail some flaws.

These critiques are well taken. As with so much of Easterbrook and Fischel's elegant framework for the corporation, ${ }^{55}$ the assumptions behind the framework prove shaky. The critiques fare less well when proposing replacements for shareholder primacy. While each critique generally seeks to expand the set of stakeholders with voting interests, the proposals are hampered by their assumption that some form of voting must be the collective choice mechanism. ${ }^{56}$ They therefore founder in describing a coherent method for aggregating the diverse preferences of multiple stakeholders. Moreover, they appear to underestimate the costs of heterogeneity. The costs of aggregating heterogeneous preferences do not only come in the form of vote cycling. As described in the next section, heterogeneity can produce inefficient outcomes even if

\footnotetext{
${ }^{51}$ Hansmann 47-49.

52 See Margaret M. Blair, Ownership and Control: Rethinking Corporate Governance for the Twenty-First Century 239 (1995); see also Lynn Emerson. Stout, The Mythical Benefits of Shareholder Control, 93 VA. L. REV. 789, 804-05 (2007) (critiquing the argument that shareholders deserve control of the firm because they are the "owners of the firm).

53 Andrei Shleifer \& Lawrence Summers, Breach of Trust in Hostile Takeovers, in CORPORATE

TAKEOVERS: CAUSES AND CONSEQUENCES (Alan J. Auerbach ed., 1988).

${ }^{54}$ See Grant Hayden \& Mathew Bodie, Arrow's Theorem and the Exclusive Shareholder Franchise, 62 Vand. L. Rev. (2009).

${ }^{55}$ See Michael Klausner, The Contractarian Theory of Corporate Law: A Generation Later, 31 J. Corp. Law 779, 780-84 (2006) (discussing the flawed assumptions behind the contractarian theory of corporate law).

${ }^{56}$ See, e.g. Haden \& Bodie, supra note 54.
} 
there is no chance of vote cycling. . is the only collective choice mechanism. They argue for expanding majority voting to other because the explanation.

\section{Alternative Organizational Forms}

The critiques of transaction cost explanations for organizational form are incomplete in another, more important, sense. Easterbrook and Fischel—and their critics- focus on control of public, for profit corporations. While the public corporation is undoubtedly an important organizational form, other forms, including close corporations, partnerships, condominiums, mutual organizations, and non profit organizations collectively deserve at least equal attention. ${ }^{57}$

Indeed, these other organizational forms may deserve heightened attention, because heterogeneity tends to be more salient in many such forms. In a public for profit corporation, heterogeneity can be eliminated through a sale of a claim in a public, liquid market. No such market exists for interests in partnerships or close corporations, or condominiums. If two partners or two condominium unit owners disagree on an important decision, one of them cannot easily sell their claim to create homogeneity. Instead, the dispute must be resolved through a preference aggregation mechanismmost commonly voting.

\section{The Direct and Indirect Costs of Majority Voting in the Presence of Heterogeneity}

The direct costs of majority voting in the presence of heterogeneity have already been described. In majority voting, heterogeneity leads to inefficiencies. Intensity of preferences cannot be accommodated in majority voting, and thus voting maximizes the welfare of the median voter, rather than maximizing efficiency. ${ }^{58}$

Existing work assumes that these voting costs are inevitable and argues that control in organizations is simply allocated to minimize the costs. But this creates an indirect cost of majority voting - the organizational modifications necessitated by the avoidance of heterogeneous control when there is majority voting. For example, Hansmann explains that non profit organizations exist because a lack of residual claimants provides assurance to an important group of stakeholders (e.g. donors), that the organization is not being controlled by a group with interests averse to those of the donors. ${ }^{59}$ But this assurance to donors comes at considerable cost. Without a class of residual claimants to monitor management, principal agent problems between management and other stakeholders may grow acute. This indirect cost of avoiding conflicts of interest in control may be nearly as large as the direct cost of majority voting in the presence heterogeneity.

\footnotetext{
${ }^{57}$ Hansmann's work, supra note xxx is a noteworthy exception, examining many different organizational forms from a transaction cost perspective. This work has received far less critical analysis

${ }^{58}$ See Levmore, Voting with Intensity, supra note 4.

${ }^{59}$ See also Eugene F. Fama \& Michael C. Jensen, Agency Problems and Residual Claims, 26 J.L. \& Econ. (1983).
} 


\section{Other Means of Collective Decision Making}

The theories described above assume that voting, and in particular majority or plurality voting, is the only means of collective decision making. In practice, this assumption is justified. The vast majority of organizations make collective decisions through voting. ${ }^{60}$ Some of the practical appeal of majority or plurality voting, however, may be due to its entrenched status within the law. Majority or plurality voting is the default standard for corporate collective action, and corporate default laws, even default laws that are ex ante inefficient for numerous organizations, are extremely sticky. ${ }^{61}$ Indeed, the one form of non-proportional voting that is explicitly permitted (though not as a default rule) by the Delaware Corporate Code, cumulative voting was employed by an average of $15 \%$ of publicly traded companies in the 1990 s. $^{62}$ Thus, the preponderance of proportional voting in practice may not be due to its inherent efficiency but rather its privileged legal status.

As a theoretical matter, the focus on majority and plurality voting is simply unjustified. There are many other collective choice mechanisms, cumulative voting being just one example. ${ }^{63}$ Each of these mechanisms entails costs and benefits. As detailed above, the costs of majority and plurality voting are considerable. Consequently, the assumption that collective decision making occurs by voting is not innocuous. Majority voting imposes costs, and organizations will evolve to minimize those costs. Thus, assuming that voting is the only means of collective decision making carries implications for all of organizational law.

In total, allocation of control rights and legal restrictions on control depend critically on the technology of collective decision making. Organizational law relies heavily on voting, and particularly majority voting, for decisions by controlling patrons. This voting mechanism has many advantages, but entails large costs in the presence of heterogeneous preferences. As a result, much of organizational law seeks to mitigate heterogeneity problems amongst the controlling patrons. In the following Sections, I seek to demonstrate how an alternative collective decision making mechanism the VCG "pivotal” mechanism facilitates efficient decision making in the presence of heterogeneity. I propose that this mechanism be offered as an option to organization, as it would remedy many current complications in corporate law, though it would introduce some novel ones.

\footnotetext{
${ }^{60}$ Cite to Hansmann, supra note $\mathrm{xxx}$.

${ }^{61}$ See, e.g., Yair Listokin, "What Do Corporate Default Rules and Menus Do? An Empirical Analysis,” forthcoming Journal of Empirical Legal Studies (2009); Henry Hansmann, "Corporation and Contract," American Law and Economics Review (2007); Omri Ben-Shahar \& John.E. Pottow, On the Stickiness of Default Rules, 33 Fla. St. U. L. Rev. 651, 651-52 (2006); Michael Klausner, Corporations, Corporate Law, and Networks of Contracts, 81 Va. L. Rev. 757 (1995).

${ }^{62}$ Paul Gompers, Joy Ishii, Andrew Metrick, Corporate Governance and Equity Prices, Quarterly Journal of Economics 107-112 (2003)

${ }^{63}$ Mueller, Public Choice, supra note $\mathrm{xxx}$, at Chapter 8.
} 


\section{III.The VCG "Pivotal" Mechanism}

\section{A. The Mechanism in Operation}

In the presence of heterogeneity in the population of controlling patrons, why not simply ask people the value they personally attribute, in dollar terms, to a given outcome? If the sum of the values attributed to a given outcome is greater than the cost of attaining that outcome, then pursue that outcome. Otherwise, do not pursue the outcome. This procedure accounts for heterogeneity. Someone who intensely desires the outcome will have a large impact on the outcome in this procedure.

There is a fatal flaw with this "mechanism", however. When asked for her preferences, an individual has no incentive to tell the truth. If she wants the government to pursue an outcome, she should tell the government that she values the outcome at an incredibly high amount rather than her true value, because this will raise the probability that the outcome that she prefers will occur. If no one is telling the truth, then the mechanism may not produce efficient outcomes, since it is not adding up true individual preferences.

The pivotal mechanism accounts for heterogeneous valuation while inducing truth telling. (The costs of the mechanism are examined below.) The mechanism induces truth telling by requiring individuals to pay for the "externality" caused by their preferences. If an individual's preferences are pivotal, changing the decision from what it would be without that individual, then that individual must pay some amount to internalize the costs imposed by that individual's preferences on the rest of the polity.

I propose that organizational law explicitly enable decision-making via the VCG "pivotal" mechanism in which all stakeholders participate. An example of the VCG mechanism is developed here. Assume that a condominium has three shareholders/unit owners, Emerson, Trump , and Thoreau, ${ }^{64}$ and is facing the choice between two decisions Basic and Lavish (As before, suppose that Basic represents minimal common amenities, while Lavish represents superior common amenities is a dissident slate. ${ }^{65}$ Further assume that all individuals have quasi-linear preferences. ${ }^{66}$ This means that there is some "numeraire" good, such as money, that can be used to measure the values of other goods in a consistent fashion, enabling the value difference between decisions Basic and Lavish to be expressed in terms of the numeraire good, which is dollars. ${ }^{67}$ For simplicity, assume that there are no other unit owners in the condominium. ${ }^{68}$ All unit

\footnotetext{
${ }^{64}$ More generally, suppose that there are $i \in I$ agents, and

${ }^{65}$ More generally, suppose that an outcome is a vector $x=\left(k, t_{1}, \ldots, t_{I}\right)$, where $k \in K$ denotes the choice of a particular outcome and $t_{i} \in \mathbf{R}$ denotes the "tax payment" of individual $i$.

${ }^{66}$ That is, $u_{i}\left(x_{i}, \theta_{i}\right)=v_{i}\left(k, \theta_{i}\right)+\left(\overline{m_{i}}+t_{i}\right)$ where $\theta_{i}$ denotes agent $i$ 's type and $\overline{m_{i}}$ denotes agent $i$ 's initial endowment of the numeraire quantity. For a discussion of quasi-linear preferences, see MWG, at 43. ${ }^{67}$ Stakeholders may care about the outcome of the decision for any reason. For example, Emerson may prefer Basic because she thinks it is immoral to have Lavish amenities, or simply because she does not have spare cash available. So long as the degree of this preference can be "monetized"--expressed in a term that can be added to the amount of money that they have in determining their overall welfare. Preferences that can be monetized in this way are termed "quasi-linear preferences, MWG at 876.

${ }^{68}$ Equivalently, we could assume that all other stakeholders are indifferent between choices Basic and Lavish.
} 
owners have \$100 in preexisting monetary wealth. Emerson, Trump , and Thoreau's relative preferences for decision Basic versus Lavish are given in Table $1 .{ }^{69}$ Emerson prefers Basic to Lavish by \$30, Trump prefers Lavish to Basic by \$40, and Thoreau prefers Basic to Lavish by $\$ 20 .^{70}$

The pivotal mechanism now must specify an outcome, Basic or Lavish, and payments for Emerson, Trump , and Thoreau. ${ }^{71}$ (For the moment, suppose that everyone tells the truth about their relative valuations.) The state, or a statewide umbrella organization of different condominium associations, asks Emerson, Trump , and Thoreau their relative valuations of Basic and Lavish. The state then adds up the net valuations for each decision and chooses the outcome with the highest total value. The total valuation of Basic sums to $\$ 50$, which is greater than the total valuation of Lavish, which sums to $\$ 40$. Thus, the Basic state of amenities (minimal amenities at low cost) is declared the victor. ${ }^{72}$

Now the VCG mechanism operator must determine payments. Unit owner Trump is not pivotal. His statement that he preferred Lavish by $\$ 40$ did not change the outcome. Thus, he pays nothing. Condo unit owner Emerson, by contrast is pivotal. Without A's statement that she preferred Basic by $\$ 30$, decision Lavish would have won rather than decision Basic. Emerson must therefore pay a VCG tax equal to the total net gains expected by Trump and Thoreau from the victory of decision Lavish in A's absence. The net benefits of Lavish in A's absence would $\$ 20=\$ 40$ [B's valuation of Y]-\$20 [C's relative valuation of Y], making A’s tax \$20. Condo unit owner Thoreau is also pivotalwithout Thoreau's valuation, decision Lavish would have defeated decision Basic by $\$ 40$ to $\$ 30$. Thus, Thoreau must pay a tax of $\$ 10$. The total VCG taxes of $\$ 30$ are passed to the government.

Table 1:

\begin{tabular}{|l|l|l|l|l|}
\hline Stakeholder & Decision & VCG Tax & $\begin{array}{l}\text { Preexisting } \\
\text { Monetary } \\
\text { Wealth }\end{array}$ \\
\cline { 2 - 5 } & $\mathrm{X}$ & $\mathrm{Y}$ & & $\$ 100$ \\
\hline $\mathrm{A}$ & $\$ 30$ & & $\$ 20$ & $\$ 100$ \\
\hline $\mathrm{B}$ & & $\$ 40$ & & $\$ 100$ \\
\hline $\mathrm{C}$ & $\$ 20$ & & $\$ 10$ & \\
\hline Total & $\$ 50$ & $\$ 40$ & $\$ 30$ & \\
\hline
\end{tabular}

Now consider Emerson, Trump , and C's incentives to tell the truth about their valuations, given that the others tell the truth. If Emerson states any (false) relative

\footnotetext{
${ }^{69}$ These valuations may include or exclude a per capita payment from each individual to finance the outcome in question.

${ }^{70}$ This follows Table 8.1 on page 160 of Mueller, Public Choice. In terms of our general framework, this example corresponds to $I=3, \overline{m_{A}}=\overline{m_{B}}=\overline{m_{E}}=\$ 100, v_{A}(X)-,v_{A}(Y)=,\$ 30$,

$v_{B}(X)-,v_{B}(Y)=,-\$ 40, v_{E}(X)-,v_{E}(Y)=,\$ 20$

${ }^{71}$ Emerson social choice function, $f($ ) in this context takes announced preferences, $\hat{\theta}$, and produces outcomes, $k() \in K$ and $t_{1}(), \ldots, t_{I}()$.

${ }^{72}$ More generally, a social choice mechanism is efficient when $\sum_{i=1}^{I} v_{i}\left(k(\theta), \theta_{i}\right) \geq \sum_{i=1}^{I} v_{i}\left(k, \theta_{i}\right)$
} 
valuation of less than $\$ 20$ for Basic, then Lavish will be the winning decision. In this case Emerson will not be pivotal, and will therefore save paying the \$20 VCG tax. Emerson will also be without decision Basic, however, which was worth $\$ 30$ to her. Thus, underreporting her value below $\$ 20$ causes Emerson to be worse off than reporting her true value of $\$ 30$. If Emerson states any value greater than $\$ 20$, then her total surplus does not change. So bidding her true value of \$30 is at least as good as any other strategy, but better than some.

Emerson is indifferent between bidding any number greater than $\$ 20$ in this example, but now suppose that Emerson does not know the sum of Trump and C's valuation for Basic. For example, C's valuation could have been $\$ 11$ instead of \$20. In this case, any number less than $\$ 30$ would leave Emerson in a worse position that stating $\$ 30$, because any number less than $\$ 30$ means that decision Lavish wins. Alternatively, C's valuation could be $\$ 9$. In this case, any (false) overstatement of value by Emerson hurts Emerson. If Emerson said \$35 when C's value was \$9, then Emerson would pay a tax of \$31, which exceeds A’s benefit from decision Basic of \$30. Thus, stating $\$ 30$ for decision Basic is better for Emerson than any other statement, and thus Emerson tells the truth. An identical calculus occurs for stakeholders Trump and Thoreau. ${ }^{73}$

We have therefore demonstrated that the VCG mechanism creates incentives for each stakeholder to tell the truth in this example. ${ }^{74}$ In turn, the truth-telling incentive insures that the VCG mechanism delivers the Kaldor Hicks efficient outcome. The mechanism chooses the outcome that maximizes the sum of aggregated utilities-which is exactly the Kaldor Hicks criterion-and these utilities are stated truthfully. So long as the $\$ 30$ paid by Emerson can be distributed to other agents in the economy and not wasted, ${ }^{75}$ then option Basic is preferred in a Kaldor Hicks sense to Lavish.

\section{B. Advantages of the Pivotal Mechanism}

The pivotal mechanism just described offers many advantages for organizations. In organizations that take decisions by voting but face considerable heterogeneity, replacing member voting by the pivotal mechanism ensures that the organization takes decisions that maximize social welfare. In organizations where control is allocated to a homogeneous group to avoid the costs of heterogeneity, the pivotal mechanism offers a

\footnotetext{
${ }^{73}$ Note that multiple equilibria are possible. The equilibria of everyone stating Basic is worth $\$ 1000$, for example, is a Nash equilibrium. No one gains from deviating in this equilibria. Nevertheless, some argue that the truthtelling equilibrium is focal in a way that these other equilibria are not. See MWG Appendix AEmerson to Chapter 23.

${ }^{74}$ Formally, it can be shown that an outcome determination, $k^{\prime}(\theta)$ satisfying the condition in footnote 72 is “truthfully implementable in dominant strategies" if, for all i, $t_{i}(\theta)=\left[\sum_{j \neq i} v_{j}\left(k^{\prime}(\theta), \theta_{j}\right)\right]+h_{i}\left(\theta_{-i}\right)$, where $h_{i}()=-\max \left(\left[\sum_{j \neq i} v_{j}\left(k^{\prime}(\theta), \theta_{j}\right)\right], 0\right)$. There are an enormous variety of published proofs of the theorem. See, e.g., MWG 877-78, Bernard Salanie, “The Microeconomics of Market Failures” 7885.

${ }^{75}$ This issue is examined infra ...
} 
means of expanding the population exercising control, with the potential for increases in efficiency along a number of dimensions.

\section{Efficient Outcomes in the Presence of Intense Preferences}

In the condominium example just described, majority voting would have produced the same outcome as the pivotal mechanism. Because Emerson and Thoreau preferred Basic to Lavish, majority voting would have yielded the efficient option (X) When preferences are particularly intense, however, majority voting can yield the inefficient outcome, while the pivotal mechanism consistently yields the efficient result.

To illustrate, suppose that condominium owner Emerson prefers option Basic (cheap amenities, low per capita cost) \$30 more than option Lavish (fancy amenities, high per capita cost), Trump values option Lavish at $\$ 60$ relative to option Basic, and Thoreau values option Basic at \$20 more than option Lavish (see Table 2 ). This example is nearly identical to Table 1, with the only exception being that B's preference for Lavish has grown more intense. In this case, the Kaldor Hicks efficient outcome is option Lavish, which has total benefits of $\$ 60$, rather than option Basic, which has total benefits of $\$ 50$. In this example, the three condo owners have extremely heterogeneous preferences. Trump intensely values option Lavish, while Emerson and Thoreau value option Basic to a smaller degree.

In the presence of such heterogeneity, voting does not produce the Kaldor Hicks efficient outcome. If Emerson, Trump , and Thoreau vote on option Basic vs. option Lavish, then Basic will receive the votes of Emerson and E. Majority voting yields option Basic rather than the more efficient Lavish.

The pivotal mechanism, by contrast, produces the efficient outcome, Lavish, by summing up the values of Emerson, Trump , and Thoreau with respect to Basic and Lavish and choosing the option with the higher sum. Lavish has a sum of $\$ 60$ while Basic has a sum of $\$ 50$. Shareholder Trump must pay \$50, while shareholders Emerson and Thoreau pay nothing. As demonstrated above, the pivotal mechanism produces incentives for all shareholders to tell the truth about their valuations, insuring that the mechanism sums honest reports of preferences and producing the efficient outcome.

Table 2:

\begin{tabular}{|l|l|l|l|l|}
\hline Stakeholder & Decision & VCG Tax & $\begin{array}{l}\text { Preexisting } \\
\text { Monetary } \\
\text { Wealth }\end{array}$ \\
\cline { 2 - 3 } & $\mathrm{X}$ & $\mathrm{Y}$ & & $\$ 100$ \\
\hline $\mathrm{A}$ & $\$ 30$ & & & $\$ 100$ \\
\hline $\mathrm{B}$ & & $\$ 60$ & & $\$ 100$ \\
\hline $\mathrm{E}$ & $\$ 20$ & $\$ 60$ & $\$ 50$ & \\
\hline Total & $\$ 50$ & $\$$ & & \\
\hline
\end{tabular}

The pivotal mechanism's superiority to majority voting in this reasonable scenario of intense preference heterogeneity supports the following recommendation. Instead of providing that condominium board of directors provide one budget for ratification by 
condo owners, ${ }^{76}$ the law should offer a second budget approval process as an option. In the new process, the board of directors formulates two budgets - a "cheap budget", with low amenities and cost, and an expensive budget, with high amenities and cost. The condo owners would then choose either option via the pivotal mechanism. Pivotal voter's payments would go either to the government or to a pool of condominium voters (see below for details). While the pivotal mechanism cannot prevent hard feelings, it can ensure efficient outcomes and assuage losers with the knowledge that some of the winners paid for their victory in cash.

\section{The Pivotal Mechanism Can Account for Other Stakeholders}

As emphasized by Hansmann, one means of avoiding the problems caused by heterogeneity is by limiting control to a homogeneous group, such as shareholders. This solution introduces costs of its own, however. Stakeholders without control are subject to potentially inefficient expropriation by controlling stakeholders whenever contracts are incomplete. The pivotal mechanism can reduce this cost by expanding to include other sets of stakeholders. ${ }^{77}$

For example, suppose that payoffs are as presented in Table 2, but that the condominium association has only one member, Trump. Thus, the condo association is perfectly homogeneous. Emerson and Thoreau are creditors of the condo association. Emerson and Thoreau prefer Basic amenities because these reduce the probability of the association's defaulting on its loan obligations.

Suppose control is allocated exclusively to the condo association by majority vote. Trump will choose Lavish amenities. This is the efficient outcome when preferences are as described in Table 2, but the inefficient outcome when preferences are represented by Table 1 This is no surprise. Creating a homogeneous group of controllers does not eliminate heterogeneity; it simply pushes other stakeholders outside the group of controllers. Emerson and Thoreau must rely on contract to protect themselves, but contracts are invariably incomplete. Emerson and Thoreau would like some control to fully protect themselves.

As a condition of the loan, Emerson and Thoreau could demand that Trump give them a vote. This will give them some protection against decisions that dilute the value of their debt. Granting votes to Emerson and Thoreau in a majority voting context, however, creates its own set of problems. If both Emerson and Thoreau get to vote on all issues, they may cause the condominium to take some inefficient decisions, as in Table 2. It is extremely difficult to tailor Emerson and Thoreau's voting interest so that they can prevent inefficient decisions like Lavish in Table 1, but cannot prevent efficient decisions like Lavish in Table 2. It is therefore no surprise that shareholders seldom share control with creditors.

The pivotal mechanism solves the problem of voting allocation. As a condition of the loan, Emerson and Thoreau could demand that they participate in the pivotal

\footnotetext{
${ }^{76}$ See, e.g., http://www.cga.ct.gov/2008/rpt/2008-R-0354.htm for a description of Connecticut's requirements for budget approval for condominiums.

${ }^{77}$ While this example focuses on other stakeholders in a condominium association, the example can easily be extrapolated to non controlling stakeholders in other types of organizations.
} 
mechanism for important decisions. As already demonstrated, the pivotal mechanism with the participation of Emerson, Trump and Thoreau produces the efficient outcome in all cases-Basic in Table 1 and Lavish in Table 2. By accommodating heterogeneity, the pivotal mechanism enables ordinarily unprotected contractual claimants of an organization to acquire a degree of control without undermining decision making. Majority voting, by contrast, has no means of expanding the set of decisionmakers without introducing the ills of preference heterogeneity.

\section{The Pivotal Mechanism and Decisional Incoherence}

Easterbrook and Fischel's account of exclusive shareholder control focuses on the risks of voting cycles produced by preference heterogeneity. Social choice theory demonstrates that unless preferences are single peaked, majority voting can produce incoherent decisions, an undesirable characteristic. In other words, if preferences do not share some important attributes, then majority voting may produce intransitive outcomes where decision A defeat B and decision B defeats $\mathrm{C}$, while decision $\mathrm{C}$ defeats $\mathrm{A}$. Easterbrook and Fischel argue that preferences of shareholders can be appropriately defined to produce voting cycles. ${ }^{78}$ Preferences of all stakeholders, by contrast, cannot. They argue that this explains why shareholder's enjoy nearly exclusive voting rights. ${ }^{79}$

This critique does not apply to multiple stakeholders aggregating choices via the pivotal mechanism. ${ }^{80}$ The pivotal mechanism produces the efficient outcome regardless of the order in which the choices are presented. In other words, the choice produced by the pivotal mechanism is exclusively a function of preferences rather than a function of preferences and voting order. The Easterbrook and Fischel preference homogeneity argument for exclusive shareholder voting therefore does not apply when the pivotal mechanism is the preference aggregating mechanism.

\section{Curing the Ills of Preference Heterogeneity and Majority Voting: The Pivotal Mechanism Versus Other Solutions}

The pivotal mechanism handles preference heterogeneity, but perhaps there are simpler solutions to the problem. This subsection demonstrates that while organizational

\footnotetext{
${ }^{78}$ Arrow, supra note 38.

${ }^{79}$ See Hayden and Bodie, supra note $\mathrm{xxx}$.

${ }^{80}$ What about Arrow's impossibility theorem? The pivotal mechanism does not apply to any set of preferences. Instead, preferences must be quasi-linear. Quasi linear preferences, where the value of goods can be expressed in terms of a numeraire quantity, is a reasonable but non-universal characterization of all choice sets. Thus, the pivotal mechanism does not violate Arrow's theorem because it fails the universal domain assumption. Shigehiro Serizawa, Power of Voters and Domain of Preferences Where Voting by Committees is Strategy-Proof, 67 J. Econ. Theory 599 (1995).
} 
law and scholarship recognizes the ills of heterogeneity, ${ }^{81}$ the solutions provided fail to yield consistently efficient outcomes.

\section{a) Vote Buying and Majority Voting does not Yield the Pivotal Mechanism Outcome}

Even if the pivotal mechanism yields efficient outcomes in the presence of preference heterogeneity, perhaps other (less radical) methods of modifying majority voting would accomodate preference intensity? One proposed solution is vote buying. ${ }^{82}$ Let stakeholders with intense preferences purchase the votes of those with less of an interest in the outcome of a vote. By purchasing votes, those with intense feelings exercise a disproportionate effect on voting outcomes, mitigating the inefficiency of majority voting. In Table 2, for example, let condo owner Trump purchase the vote of condo owner Thoreau for \$20. With C's vote in hand, Trump casts two votes for option Lavish, allowing Lavish to triumph. Thus, vote buying enables majority voting to produce efficient outcomes in some contexts where preference intensities would ordinarily make the outcome of majority voting inefficient.

Unfortunately, this benefit of vote buying is not the end of the story. While vote buying under majority voting can cure some inefficiencies resulting from preference heterogeneity, vote buying also introduces the possibility of inefficiencies in other circumstances. Consider the example set forth in Table 1. If everyone votes their personal preferences, then efficient decision Basic defeats Lavish in majority voting by a two to one margin. Now, however, suppose that vote buying is allowed. Condo owner Trump can offer owner Thoreau \$30 for C's vote. This price is greater than the value of the vote to Thoreau, but less than the value of the vote to Trump . With C's vote in hand, Trump can cast two votes in favor of Lavish, producing a victory for Lavish, in spite of Trump's inefficiency relative to Basic. C's sales of the vote to Trump imposes an externality on Emerson (who no longer gets desired outcome X). Neither Trump nor Thoreau internalize the externality, however, allowing an inefficiency to occur.

If Emerson can get involved in the negotiation, then Emerson and Thoreau can agree on some payoff that makes Thoreau better off than if she sold her vote to Trump . The transaction costs of this three way negotiation are likely to be high, however. Moreover, as the number of voters rises, the number of bilateral negotiations rises combinatorically, meaning that transaction costs will quickly make the "transfer" solution to vote buying impractical. ${ }^{83}$

\footnotetext{
${ }^{81}$ See, e.g., Gillian Hadfield, On Public Versus Private Provision of Corporate Law, 22 J.L. Econ. \& Org. 414 (2006).

82 Richard L. Hasen, Vote Buying, 88 Cal. L. Rev. 1323, 1370 (2000); Levmore, supra; Susan E. K. Christoffersen et al., The Market for Record-Date Ownership 7 (July 4, 2002) (unpublished manuscript), available at http:// ssrn.com/abstract $=302522$.

${ }^{83}$ See Joseph Farrell, Information and the Coase Theorem, J. Econ. Persp., Fall 1987, at 113.
} 
Given these costs, it is no surprise that vote buying is generally prohibited. ${ }^{84}$ While vote buying can ameliorate the inefficiencies associated with majority voting in the presence of intense preferences, vote buying also introduces inefficiencies that outweigh the gains. The pivotal mechanism, by contrast, yields the efficient outcome in all situations. Moreover, arriving at the efficient outcome does not require high transaction cost multilateral bargaining. In total, vote buying cannot achieve the same outcomes as the pivotal mechanism while retaining majority voting.

\section{b) Fiduciary Duties and other Modified Voting Rules for Majority Owners do not Match the Pivotal Mechanism}

Majority control of an organization such as a condominium creates another form of preference heterogeneity that causes problems for majority voting. For example, suppose that Emerson buys Thoreau's condominium unit. Further suppose that Emerson is a small scale contractor, able to construct Basic amenities but unable to create lavish ones. Emerson's preferences for Basic amenities reflects the fact that Basic amenities will be constructed (at a profit) by Emerson, while lavish amenities must be constructed by an alternative contractor. The net benefits of Basic and Lavish options remain as described in Table 2. ${ }^{85}$ In a majority vote for control of the condominium board, Emerson will win control with two votes. Emerson will exercise control to choose Basic, in spite of the fact that Lavish is efficient. Organizational law limits Emerson's ability to choose Basic by establishing a fiduciary duty for a board of directors to maximize the condominium's best interests rather than their own. ${ }^{86}$ If the condominium board chooses Emerson's company to provide the Basic amenities, that transaction would be subject to a stringent duty of loyalty with the burden of proof upon Emerson to demonstrate to the court that the transaction benefitted the association as a whole.

One way to overcome this burden is by demonstrating that a "majority of the minority" approved the transaction. ${ }^{87}$ In this case, Emerson will not win such a vote. Trump, the sole minority shareholder, will vote against Basic amenities. Thus, the fiduciary duty rules prevent Emerson from choosing inefficient decision Basic.

So do fiduciary duty rules and "majority of the minority" solve majority voting's difficulties with preference heterogeneity in controlling shareholder contexts? Again, the answer is no. Take the facts as before, but assume that Trump values Lavish at $\$ 40$ (as in Table 1) rather than $\$ 60$ (as in Table 2). In this case, Basic is the efficient outcome.

\footnotetext{
${ }^{84}$ The first Restatement of Contracts, for example, prohibited vote buying. Restatement (First) of Contracts $\S 569$ (1932) ("A bargain by an official or a shareholder of a corporation for a consideration enuring to him personally to exercise or promise to exercise his powers in the management of the corporation in a particular way is illegal.”). Though shareholder votes could not be sold, they could (and still can) be transferred without consideration, such as through a proxy agreement. See Rev. Model Bus. Corp. Act $\S$ 7.22(b) (Supp. 1997). In this way, corporate votes have always differed from votes in political elections. See supra text accompanying note 64 .

${ }^{85}$ Emerson may get less utility from Basic for his new unit (formerly Thoreau's) because Thoreau's unit might be better situated to take advantage of lavish amenities. E.g., its near the health club.

${ }^{86}$ Munder v. Circle One Condominium, Inc., 596 So. 2d 144 (Fla. Dist. Ct. App. 1992), aff'd 1994 Fla. App. LEXIS 6668 (July 28, 1994) (condominium context); 18A Am. Jur. 2d Corporations § 644 (fiduciary duty of controlling shareholder in corporate context).,

${ }^{87}$ See Emerald Partners v. Berlin, 726 A.2d 1215, 1223 (Del. 1999);
} 
Under a majority of the minority requirement, however, Lavish will win, because Trump prefers Lavish. Emerson could force through Basic and hope that he will be able to demonstrate that Basic is indeed efficient. This is a risky strategy, however. The burden of proof is on Emerson and that it will be difficult to for a court to determine that Basic is indeed efficient. Emerson could of course give Trump a payoff to induce Trump to support Basic, but the transaction costs of such an arrangement may be high and would grow higher with more participants with heterogeneous preferences.

In total, the fiduciary duty/majority of the minority limitation on controlling shareholders does not inevitably produce the efficient outcome when there are controlling shareholders. The pivotal mechanism, by contrast, yields the efficient outcome in both contexts without elaborate judicial involvement or high transaction costs. Thus, the pivotal mechanism appears superior to majority voting in handling preference heterogeneity caused by the existence of a controlling shareholder.

This section demonstrated the considerable promise of the pivotal mechanism in aggregating heterogeneous preferences by organizational stakeholders.

\section{Costs of the Pivotal Mechanism}

The pivotal mechanism is no panacea. High direct costs and difficulties in distributing revenues collected, the possibility of collusion, agenda control, income limitations, and difficulties defining the group of participants suggest that the pivotal mechanism will not be practicable in some contexts. This section examines these difficulties and explores some potential remedies.

While the difficulties associated with the pivotal mechanism are real, they should be placed in context. All collective decision making mechanisms are subject to complications, and rather than dismissing the mechanisms due to their complications, laws and norms have developed to mitigate the costs associated with the complications. For example, majority voting produces inefficient outcomes when individuals seek to buy votes or when majorities oppress minorities. Instead of discarding majority voting entirely, democracies and organizational democracies have enacted laws prohibiting vote buying and providing protections to minorities. Similarly, market allocation mechanisms cease to be efficient in the presence of collusive oligopolies or monopolies and are prone to periodic crises. ${ }^{88}$ Market economies have developed antitrust laws and bank guarantee programs to minimize the flaws of the market while retaining its benefits. ${ }^{89}$

The pivotal mechanism is untested, and therefore rules that mitigate its flaws are undeveloped. Moreover, scholars and rulemakers know relatively little about the significance of the various flaws. Given the real benefits of the pivotal mechanism and the absence of any perfect collective choice mechanism, these are reasons to further explore the mechanism rather than jettisoning it. Indeed, the untested nature of the pivotal mechanism creates an argument for public development of the mechanism rather than relying on private sector innovation. ${ }^{90}$ Early adopters will be guinea pigs, experimenting with various solutions to the pivotal mechanism's flaws. These early adopters will bear

\footnotetext{
${ }^{88}$ See generally Guy Sagi, The Oligopolistic Pricing Problem, 2008 Colum. Bus. L. Rev. 269.

${ }^{89}$ For a related discussion of the relationship between antitrust problems and the market for corporate control, see Joshua M. Fried et al., Collusive Bidding in the Market for Corporate Control, 79 Neb. L. Rev. 48 (2000).

${ }^{90}$ See generally, Yair Listokin, Learning Through Policy Variation, 118 Yale L.J. 480 (2008).
} 
all the costs of failed efforts. Successful solutions to the flaws, or even evidence that the difficulties are not as salient as expected, provide benefits to all potential future users of the pivotal mechanism. Thus, there will be an inefficiently small amount of private innovation regarding the pivotal mechanism. Public investment in the mechanism addresses this public goods problem. So long as the expected benefits of the investment in the pivotal mechanism exceed the direct costs of public sector experimentation, government should engage in some public development of the pivotal mechanism.

Finally, it should be emphasized at the outset that the pivotal mechanism should be offered as a menu option. No organizations will be forced to adopt the pivotal mechanism, meaning that the mechanism is unlikely to be adopted in contexts where the costs described here are particularly salient. The optional nature of the pivotal mechanism raises the chance that it will be welfare enhancing. ${ }^{91}$

With this context in mind, the remainder of this section examines the costs of the pivotal mechanism.

\section{Direct Costs of the Pivotal Mechanism}

Any decision making that requires the participation of many parties is an expensive one. Individuals not actively involved in an organization's function must take the time to learn about the decision being confronted, a costly process. This explains why most organizational decisions are not taken by a collective decision making mechanism, but rather by individual agents.

The pivotal mechanism is no exception. Indeed, the costs of collective decision making via the pivotal mechanism may be even higher than the costs of collective decision making via majority vote. Because the pivotal mechanism is more complicated than ordinary majority voting, simply educating shareholder of an organization such as a condominium association about the functioning of the mechanism will be costly. ${ }^{92}$ In addition, the pivotal mechanism demands more from participants than majority voting. Voting simply requires voters to choose their preferred alternative, while the pivotal mechanism demands that participants place a dollar value on their relative preferences. If individuals decline to participate due to these costs, then the efficiency benefits of the pivotal mechanism may be lost.

This complexity implies that the pivotal mechanism should be applied to collective decision making with large effects, in which the relatively fixed costs of holding a vote can be offset by potentially larger benefits. Again using the condominium association example to illustrate the main points, ${ }^{93}$ the condo should not choose the soap to place in its public bathrooms via the pivotal mechanism - the costs of setting up the mechanism outweigh the benefits. If the condominium is debating a comprehensive and

\footnotetext{
${ }^{91}$ Once organizations choose to adopt the mechanism, they will be compelled to take some decisions via the mechanism. This is an analogous to the setup of corporation law. Organizations are not required to become corporations, but once they decide to become corporations, they must undetake a periodic election of board of directors, among other requirements. For more details, see the section on agenda setting below.

${ }^{92}$ Cf. Brad J. Kieserman, Comment, Profits and Principles: Promoting Multinational Corporate Responsibility by Amending the Alien Tort Claims Act, 48 Cath. U. L. Rev. 881, 993 (1999) (discussing how nonprofit institutions are attempting to fill the gap by educating shareholders).

${ }^{93}$ Any of the other applications discussed in Section xxx below could also be used for illustrative purposes.
} 
expensive remodeling of public amenities, however, then the efficiency gains from choosing the right level of amenities may outweigh the costs.

Organizational law should respond to these costs. Just as corporate law requires relatively few shareholder votes, ${ }^{94}$ so too should a framework for a pivotal mechanism insist upon relatively infrequent application. The pivotal mechanism could be required for the condominium association's annual budget, or for expenses exceeding a certain threshold, but not for other decisions. Indeed, one initial rule for the pivotal mechanism would be to require the mechanism's application whenever existing law requires a vote.

The pivotal mechanism also has some idiosyncratic direct costs; it requires some subset of participants to pay money in some instances. The money raised by the pivotal mechanism cannot be distributed in a way that disturbs the pivotal mechanism's truth telling properties. If an individual received a redistribution that is a function of her own report of value, then the truth-inducing incentives of the pivotal mechanism are distorted. The individual would have an incentive to report false preferences, knowing that these reports would affect her payment. As a result, redistribution of the payments cannot depend upon on an individual's valuation report. ${ }^{95}$ This restriction means that the funds raised by the pivotal mechanism cannot simply be redistributed pro rata to the participants.

If the money raised by the pivotal mechanism is simply wasted, then the truth telling properties of the mechanism are undisturbed but the mechanism is no longer as attractive because it involves large amounts of waste. ${ }^{96}$ Other methods of redistribution, however, allow the payments to go unwasted without distorting incentives. They may involve the payment of money to individuals outside the organization, however. ${ }^{97}$ For example, all pivotal mechanism payments could go to the government. While this would avoid waste, it would be unattractive for any organization to unilaterally adopt the mechanism under these circumstances.

There are several alternative solutions. One possibility is to sell the rights to the funds collected by the mechanism to a third party. The third party's payment would presumably reflect the expected value of the expected pivotal mechanism payments. For example, the condominium association could agree to vote on its annual budget via the pivotal mechanism and grant the proceeds to an insurance company in exchange for some up front payment. In a competitive market, the insurance company will pay the condominium association the expected value of the payments, making the payments to the mechanism neutral. An alternative solution is to have similar organizations trade claims to pivotal mechanism payments. ${ }^{98}$ If there are two organizations, $\mathrm{H}$ and $\mathrm{I}$, then company I will receive all pivotal mechanism payments made with respect to organization $\mathrm{H}$, organization $\mathrm{H}$ will receive all pivotal payments made with respect to organization I. If organizations $\mathrm{H}$ and I have similar expected pivotal mechanism

\footnotetext{
${ }^{94}$ For a summary of theories explaining why there are few corporate votes, see Robert B. Thompson \& D. Gordon Smith, Toward a New Theory of the Shareholder Role: "Sacred Space" in Corporate Takeovers, 80 Tex. L. Rev. 261, 273-4 (2001).

${ }^{95}$ Mueller, supra note xxx, at 166-67.

${ }^{96}$ Mueller, supra note $\mathrm{xxx}$, at $161,166$.

${ }^{97}$ If an organization unilaterally adopts the pivotal mechanism and transfers the resulting payments outside the organization, then the mechanism would be wasteful from the perspective of the organization adopting the mechanism, even though such a transfer is not wasteful from a social perspective.

${ }^{98}$ Mueller, supra note xxx, at 166.
} 
payments, then from an ex-ante perspective the pivotal mechanism is revenue neutral for each organization. If even this proves unworkable, then there are other more complicated mechanisms for redistributing revenue within the organization that do not distort truthtelling incentives. ${ }^{99}$

In total, while there is no question that the pivotal mechanism is costly, it does not appear that these costs make the mechanism impractical for important decisions.

\section{Problems of Agenda Control}

To this point, the discussion has assumed the existence of two options, Basic and Lavish, for the condominium association. Given these choices, the pivotal mechanism produces the efficient outcomes. But how do these options get onto the agenda and get chosen via the pivotal mechanism? If the ability to control the agenda changes the choices presented to participants in the pivotal mechanism, then the mechanism may not achieve its purported benefits.

The issue of agenda control is not unique to the pivotal mechanism. ${ }^{100}$ Indeed, the pivotal mechanism is in some respects more robust than majority voting with respect to agenda control. For example, the pivotal mechanism can allow much broader access to proposal for a particular iteration of the mechanism than majority voting. If everyone on the condominium association presents a budget, for example, then each member can evaluate each option and provide a "schedule" of dollar values for the various options. The introduction of additional choices does not change the outcome. In majority voting, by contrast, the order in which choices are presented can lead to different outcomes. Thus, a highly decentralized form of agenda setting is one option for allowing choices such as Basic of Lavish to come before the condominium owners.

Even though the pivotal mechanism may cost participants money, they will still prefer to bring items onto an agenda rather than sitting out. The pivotal mechanism already implicitly includes a "sit out" option. Individuals can bid zero, and have no risk of making payments. The "truth telling" element of the mechanism, however, insures that individuals will prefer to state their true preferences (including revealing their preferred proposal) rather than falsely reporting no interest. In total, once the pivotal mechanism is introduced, the ability to place items on the menu for the mechanism can be broadly shared.

The pivotal mechanism is acutely sensitive to agenda setting with respect to vote timing, however. Suppose that Trump in Table 1 can run the pivotal mechanism for the condominium as many times as desired. Trump may choose to run the mechanism continually, forcing Emerson and Thoreau to constantly make payments to insure option Basic. Knowing this, Emerson and Thoreau may prefer to concede rather than bidding their relative values for Basic and Lavish, because a Basic victory in one round does not produce Basic but rather simply insures another costly iteration of the mechanism. If the issue were decided by majority vote, however, the "cost” to Emerson and Thoreau of

\footnotetext{
${ }^{99}$ See, e.g., Martin Bailey, The Demand Revealing Process: To Distribute the Surplus, 91 Public Choice 107 (1997).

${ }^{100}$ See, e.g., Douglas A. Irwin, Antebellum Tariff Politics: Regional Coalitions and Shifting Economic Interests, 51 J.L. \& Econ. 715, 729 (2008) (discussing an example of the importance of agenda control in legislative decision making).
} 
choosing Basic repeatedly is reduced, diminishing Trump’s incentive to repeatedly bring the identical item to a decision.

Because of this complication, the pivotal mechanism is best suited for fixed timing agendas. For example, if a condominium chooses the pivotal mechanism, then it should be required to take some decisions via the pivotal mechanism and these decisions should be binding for some period. For example, the law might require that condo budget decisions are made via the pivotal mechanism and that the outcome of these decsisions is binding for one year. ${ }^{101}$ Relatedly, the law might provide that certain momentous decisions, such as whether to merge with another condo association, must be taken by pivotal mechanism, with the decision binding for some period of time.

\section{Incentives for Truth Telling and Coalitions}

Another obstacle to the pivotal mechanism is the possibility of coalition formation. Coalition formation may distort truth telling incentives in the pivotal mechanisms, and prevent the mechanism from producing an efficient outcome. ${ }^{102}$

To illustrate, return to Table 2. In this example, outcome Lavish is efficient. Suppose, however, that Emerson and Thoreau know Trump's valuation and form a coalition, agreeing to each bid $\$ 100$. In that case, option Basic would win with a value of \$200. In addition, neither Emerson nor Thoreau would have to make payments because neither is pivotal. Without Thoreau, Basic would get a value of $\$ 100$, which is greater than Trump's value of $\$ 60$. Thus, Thoreau's bid is not pivotal-Basic is chosen without Thoreau's bid. Similarly, without Emerson, Basic would get a value of \$100, meaning that Emerson is not pivotal. Moreover, Trump has no incentive to change their bid-even if Trump knows about the coalition between Basic and Lavish, Trump can only alter the outcome to Lavish by bidding over $\$ 200$, which would require Trump to make a payment (\$200) that is greater than B’s preference for Lavish. By forming a coalition and telling false outcomes, Emerson and Thoreau get their desired result-Basic-- without having to make payments. Option Basic, however, is inefficient. As a result, if Emerson and Thoreau can form a coalition like the one described, the efficiency generating characteristics of the pivotal mechanism are distorted.

Table 2:

\begin{tabular}{|c|c|c|c|c|c|c|}
\hline \multirow[t]{2}{*}{ Stakeholder } & \multicolumn{2}{|c|}{ Decision } & & \multirow{2}{*}{$\begin{array}{l}\text { VCG } \\
\text { Tax }\end{array}$} & \multirow{2}{*}{$\begin{array}{l}\text { VCG Tax } \\
\text { When } \\
\text { Coalitions } \\
\text { are Formed }\end{array}$} & \multirow{2}{*}{$\begin{array}{l}\text { Preexisting } \\
\text { Monetary } \\
\text { Wealth }\end{array}$} \\
\hline & $\mathrm{X}$ & $\begin{array}{l}\text { X- } \\
\text { Coalition }\end{array}$ & $\mathrm{Y}$ & & & \\
\hline $\mathrm{A}$ & $\$ 30$ & $\$ 100$ & & & $\$ 0$ & $\$ 100$ \\
\hline B & & & $\$ 60$ & $\$ 50$ & $\$ 0$ & $\$ 100$ \\
\hline $\mathrm{E}$ & $\$ 20$ & $\$ 100$ & & & $\$ 0$ & $\$ 100$ \\
\hline Total & $\$ 50$ & $\$ 200$ & $\$ 60$ & $\$ 50$ & $\$ 0$ & \\
\hline
\end{tabular}

${ }^{101}$ The agenda of some votes subject to majority voting is similarly proscribed by law. Democratic elections in the United States, for example, generally take place at fixed intervals.

102 Mueller, supra note xxx, at 167-68; Elaine Bennet \& David Conn, The Group Incentive Properties of Mechanism for the Provision of Public Goods, 29 Public Choice 95 (1977). 
Tullock notes that the problem of coalition formation may not be particularly prevalent. ${ }^{103}$ If Emerson and Thoreau are not certain about B's valuation, then their incentives to report a false valuation are weakened. If B's valuation of Lavish is \$150, for example, then Emerson and Thoreau will have to pay \$50 each. Thus, uncertainty weakens Emerson and Thoreau's incentive to form a coalition.

In addition, both Emerson and Thoreau will have incentives to defect from the coalition. If Emerson knows that Thoreau will report \$100 and does not know B's valuation, then A’s optimal report is \$30. By reporting \$30, Emerson insures that he pays nothing if B's valuation is under $\$ 100$ or greater than $\$ 130$ (assuming that Thoreau reports \$100). If Trump reports a number between $\$ 100$ and $\$ 130$, then Emerson will make a payment, but will receive the desired outcome. Thus, a coalition where both Emerson and Thoreau report \$100 is inherently unstable. Finally, coalition formation can be prohibited, much as cartelization is banned under antitrust laws. If collusion is illegal, incentives to collude will be diminished because the costs of collusion will rise.

\section{Determining Eligible Participants in the Mechanism}

In some respects, defining the set of eligible participants assumes greater significance for majority voting than it does with respect to the pivotal mechanism. Overexpansion of the set of majority voters can lead to extreme heterogeneity and inefficient outcomes. With the pivotal mechanism, by contrast, the heterogeneity introduced by a large set of participants is less problematic. The mechanism produces the efficient outcome for the entire set of participants, regardless of the participant's differences in opinion.

In other circumstances, however, the definition of the set of pivotal mechanism participants assumes critical importance. For example, the problem of collusion grows worse if two participants in the pivotal mechanism can be controlled by the same unit. If Emerson and Thoreau are controlled by the same source (.e.g. Emerson), then the "defection" obstacle to coalition formation becomes insignificant. With two chances to participate in the pivotal mechanism and no chance of defection, Emerson could induce the Emerson and Thoreau condo units to falsely bid \$1000 each for Basic. Basic would win in this instance, even when it is inefficient.

To prevent this inefficiency, the law should develop rules against multiple participation in the mechanism by the same party. These rules should be strict-if interests are significantly overlapping then they should be required to make a single report. If Emerson owns two units in a condominium association, he should only enjoy one chance to participate in the pivotal mechanism. Emerson's bid may be large because his interests are spread over multiple units. Unlike inefficient collusive bidding, however, this form of bidding is efficient, however, truthfully reflecting Emerson's preferences. ${ }^{104}$

\footnotetext{
${ }^{103}$ Gordon Tullock, Demand Revealing Process, Coalitions and Public Goods, 29 Public Choice 103 (1977).

${ }^{104}$ Cf. Edward B. Rock, Antitrust and the Market for Corporate Control, 77 Cal. L. Rev. 1365, 1372-73 (1989).
} 
A variant of empty voting could also create inefficiences in some contexts. Suppose that Trump purchased a condominium not because he wanted to live in the condominium, but rather because he wanted to create a neighbor with nicer amenities to his development next door. Through participation in the pivotal mechanism, Trump could enable Lavish to win, in spite of the fact that Lavish is not the efficient choice for the true residents of the condominium.

This outcome is not inefficient per se-Lavish will only win if it is efficient. Indeed, it could be argued that this a virtue of the pivotal mechanism-it internalizes the externality of nice amenities on the value of nearby real estate. Nevertheless, outcome Lavish represents a loss of control for the residents of the condominium. Moreover, the residents are not directly compensated for the loss. In contexts where complete control is essential for transacting for some class of stakeholders, it is unlikely that the original set of controlling stakeholders will choose to make decisions via the pivotal mechanism.

If the original set of voting stakeholders view the pivotal mechanism as a worthwhile investment in spite of the loss of control, they may adopt several techniques to reduce the costs of the loss of control. For example, the controlling voters could retainr control, such as veto rights, over the entrance or exit of other participants in the mechanism. By vetoing Trump, Emerson and Thoreau could avoid loss of control of their condominium association. Alternatively, they could require some aspects of majority voting, such as a requirement that an option be favored by at least a certain number of residents before it can be approved via the pivotal mechanism.

When an organization transacts with several diverse groups of stakeholders with considerable intra-group homogeneity, then a hybrid of majority voting and the pivotal mechanism can mitigate the problem of defining the set of participants. Each group can pick a single representative by majority vote, and this representative will take part in the pivotal mechanism. ${ }^{105}$ For example, suppose that Emerson and Thoreau are creditors of the condominium association, while Trump is the sole resident. Suppose Emerson and Thoreau choose Emerson as their representative and that Trump chooses himself. Emerson and Trump then participate in the pivotal mechanism. If Emerson and Thoreau have identical preferences, then Emerson will perfectly internalize Thoreau's preferences in the mechanism. The mechanism will therefore yield the efficient outcome. In addition, the possibility of collusion between Emerson and Thoreau is eliminated-only one can participate. Moreover, the resident's loss of control is explicit-they grant creditors a right to participate in the mechanism - rather than subject to subversion, as would occur if creditors bought a unit in the condominium for the purpose of maximizing creditor interest via the pivotal mechanism rather than resident interest. This combination of majority voting and the pivotal mechanism, like some of the other modifications discussed above, provides many (but not all) of the benefits associated with the pivotal mechanism while mitigating some of the mechanism's salient costs.

\footnotetext{
105 This would be similar to the practice of voting by proxy in corporate law. For a discussion of the comparison between corporate governance quality and proxy voting, see Sanjai Bhagat, Brian Bolton \& Roberta Romano, The Promise and Peril of Corporate Governance Indicies, 108 Colum. L. Rev. 1803 (2008).
} 


\section{Income and Wealth Limitations}

In situations where monetary valuations are extremely difficult or reflect deep preferences with non-monetary values, the pivotal mechanism would likely be difficult to put into operation. ${ }^{106}$ For instance, implementing the pivotal mechanism in the context of union voting might require workers to place a cost on the value of union representation relative to non-union representation.

And even when preferences can be monetized, the pivotal mechanism measures intensity of preferences by someone's ability to trade dollars for a given outcome. While this is a good measure of intensity of preferences and social welfare under the assumption of quasi linear utility, it has obvious limitations. This Section examines these limitations.

Preference reports must be feasible. An individual may feel strongly about an issue, but they cannot report a preference that is greater than their lifetime supply of the numeraire quantity - money. Any pivotal mechanism will therefore have to verify that an individual can actually pay their reported valuation if they are pivotal before allowing an individual to participate in the mechanism.

But this implies that wealthier individuals, with a larger budget constraint, will have greater ability to express intense preferences, even if poorer individuals feel just as strongly about a certain outcome. Indeed, this is a good argument against using the pivotal mechanism as a substitute for citizen democracy. Democracies may have a strong presumption that all individuals "count” equally, even if they have different resources. This presumption is less powerful when it comes to organizations in the productive sector. These are already presumed to maximize economic interests rather than other interests. At present, for profit organizations are controlled to maximize the economic interest of shareholders. Enabling other stakeholders to take part in control, even if their ability to participate is related to their wealth, expands rather than constricts their ability to participate.

It should also be emphasized that the welfare enhancing properties of the pivotal mechanism are derived from a partial equilibrium analysis. This means that the results of the pivotal mechanism do not change demand for other goods. If this assumption is false, then it is possible that welfare is not maximized by the pivotal mechanism. Emerson partial equilibrium analysis also ignores the wealth effects of the mechanism. These may be considerable. In some cases, pivotal individuals may pay considerable portions of their wealth into the mechanism, which will have effects on other markets as well. ${ }^{107}$ If these wealth affects are widespread, then we should have less confidence that the pivotal mechanism produces outcomes that are socially optimal.

Groves and Ledyard have developed a general equilibrium alternative of the pivotal mechanism. ${ }^{108}$ This alternative provides efficient outcomes that are robust to

\footnotetext{
${ }^{106}$ Cf. Sameer H. Doshi, Making the Sale on Contingent Valuation, 21 Tul. Envtl. L.J. 295 (2008) (discussing contingent valuation, a method of attempting to monetize the value of nontradable public goods).

${ }^{107}$ Although the wealth effects on individuals may be substantial, the total wealth effects on all individuals participating in the mechanism (including those who are not pivotal) may be small enough that the partial equilibrium analysis ignoring wealth effects may be a reasonable approximation of true social welfare.

${ }^{108}$ Theodore Groves and John Ledyard, Optimal Allocation of Public Goods: Emerson Solution to the Free Rider Problem, 45 Econometrica 783 (1987).
} 
"knock on" effects such as the effect of the mechanism on the wealth of participants. Their mechanism also allows a broader range of utility functions than the pivotal mechanism, which presumes that utility is quasi-linear. ${ }^{109}$ This advantage of the Groves Ledyard variation is offset by several disadvantages. Most prominently, the efficient solution in the Groves Ledyard mechanism is a much less stable equilibrium than the pivotal mechanism equilibrium. In addition, the Groves Ledyard mechanism is considerably more complex than the pivotal mechanism. As a result, I believe that the pivotal mechanism, in spite of its limitations, provides more value added than the Groves Ledyard mechanism.

This subsection demonstrated that the pivotal mechanism is no panacea. The pivotal mechanism engenders some significant costs. The size of these costs (as well as the size of the mechanism's benefits) varies with the organizational context. When absolute control is essential or when wealth disparities loom large, the mechanism's defects may be insoluble. The pivotal mechanism may be a poor collective choice procedure in these contexts. In still other contexts, modifications of the pivotal mechanism may mitigate the costs, making the pivotal mechanism attractive. This is likely to occur when heterogeneity looms large for an organization and when the modifications discussed in this section are most feasible.

In total, the argument in favor of the pivotal mechanism is not that it is unequivocally better than collective choice through majority voting. Rather, the pivotal mechanism's greatest virtue is that it offers different costs and benefits than existing organizational collective choice mechanisms. By meaningfully expanding the range of organizational form, the pivotal mechanism adds value as a menu option for organizational choices.

\section{Can It Work? Evidence from Auctions}

Even if the "menu" aspect of the pivotal mechanism reduces its potential costs, the list of potential complications just discussed raises an obvious question--can the pivotal mechanism ever function as a practical method of allocating control of organizations? Several examples provide some evidence that the pivotal mechanism can produce efficient outcomes.

In a series of lab experiments, Smith and others examined whether the pivotal mechanism produced efficient outcomes. The mechanism consistently did, suggesting that the theoretical liabilities of the pivotal mechanism do not prevent it from producing "good" outcomes in practice. ${ }^{110}$

Even better evidence of the pivotal mechanism's practicality comes from real-life auction mechanisms. To maximize revenue and allocate scarce resources to firms valuing them the most, economists recommend auction procedures that are analytically very similar to the pivotal mechanism. ${ }^{111}$ The goal is to induce individuals to reveal their true valuation of a good and allocate efficiently by having the allocation of the good depend upon everyone's report (the good goes to the highest reporter) without the price paid by

\footnotetext{
${ }^{109}$ See text around note 66 for a discussion of quasi linear utility.

${ }^{110}$ See, e.g., Vernon L. Smith, Experiments with a Decentralized Mechanism for Public Good Decisions, 70 American Economic Review 584 (1980).

${ }^{111}$ See Charles Holt et, al, Auction Design for Selling CO2 Emission Allowances Under the Regional Greenhouse Gas Initiative (2007), available at http://www.rggi.org/docs/rggi_auction_final.pdf.
} 
any individual depending upon their own report (the winning bidder pays the second highest bid, rather than the highest). This second price auction mechanism has truthtelling properties very similar to the pivotal mechanism. The mechanism is similarly vulnerable to collusion and should be similarly costly. ${ }^{112}$ In spite of these problems, the mechanism has been recommended by an expert panel, for use in auctioning Carbon Dioxide emissions permit through the United States' first large-scale greenhouse gas trading market. ${ }^{113}$ The panel reviewed a large body of empirical research examining mechanisms, and concluded that the pivotal mechanism analogue was practical. ${ }^{114}$ Thus, the efficacy of the spectrum auctions provides evidence regarding the practical applicability of the pivotal mechanism.

\section{Applications and Extensions}

To this point, the costs and benefits of the pivotal mechanism has been examined in a narrow context-determining a condominium association's level of public amenities. The pivotal mechanism's advantages, however, apply more generally. Whenever the costs of heterogeneity are salient and the problems of agenda control and collusion can be mitigated, the pivotal mechanism offers large potential benefits. This section discusses two such contexts-bankruptcy decision making and partnership and close corporation collective decision making - in some detail. The section concludes by briefly discussing other potential applications for the pivotal mechanism in more speculative fashion.

\section{A. Close Corporations and Partnerships}

In small corporations and partnerships, heterogeneity within the set of controlling stakeholders is the norm. ${ }^{115}$ Shareholders of such firms are often also employees of the firm, so their control decisions reflect a combination of both roles. If two individuals with equal controlling stakes assume different labor roles, then their control preferences are more likely to be heterogeneous. In addition, close corporations may have majority shareholders, leaving minority shareholders vulnerable to various forms of expropriation. While fiduciary duties of loyalty limit the expropriation, they introduce costs of their own. Finally, residual claimants of small firms are often undiversified. If different shareholders have diverse risk preferences, then there may be conflicts over the best direction for the firm. Risk loving shareholders may prefer aggressive expansion, while cautious shareholders prefer to avoid taking chances. ${ }^{116}$ All these factors raise the risk that majority voting produces inefficient outcomes.

Consider law firm partnership decision making. Partners in one office of the firm or one practice area may seek to expand that office or practice area, while partners elsewhere evince no such desire. Very successful partners may want to restrict the partnership to avoid diluting their equity shares, while others may prefer to keep make control of the firm more diffuse. Young partners with long expected tenures may be

\footnotetext{
112 See Holt et. Al, at 45-53.

113 See Holt et. Al, at 77-78.

114 See Holt et. Al, at 77-78.

115 See generally Grant M. Hayden \& Matthew T. Bodie, One Share, One Vote and the False Promise of Shareholder Homogeneity, 30 Cardozo L. Rev. 445 (2008).

${ }^{116}$ See generally Julian Velasco, Taking Shareholder Rights Seriously, 41 U.C. Davis L. Rev. 605 (2007).
} 
anxious to make long term investments that depress short term profits, while partners near retirement may dislike such investments. In each case, such heterogeneity may lead to inefficient decision-making. Majority voting produces the outcome preferred by the median partner, but this may not be the efficient decision if the minority cares more intensely than the majority, as is likely the case with such heterogeneous preferences.

The pivotal mechanism, by contrast, yields efficient outcomes in the presence of varying preference intensities. This benefit is particularly salient in the close corporation or partnership context, where there is likely to be high preference heterogeneity. In addition, the costs of the pivotal mechanism are likely to be manageable in these contexts. Wealth and income disparities are often relatively small among different shareholders of the same corporation. The set of eligible participants in the pivotal mechanism is also relatively easily defined-all partners can take part. Collusion between partners is a risk, but as described above these cartels are inherently unstable. Moreover, the risk of collusion could be mitigated by legal prohibition of explicit collusion. In total, partnerships and close corporations constitute favorable contexts for application of the pivotal mechanism.

\section{B. Bankruptcy}

Heterogeneity of stakeholders looms large in bankruptcy. The costs and benefits of particular decisions may fall on any number of stakeholders, including employees, secured creditors, senior creditors, junior creditors, or equityholders. ${ }^{117}$ Because it is extremely difficult to tell which stakeholders are most affected by a decision, the appropriate allocation of control in bankruptcy is problematic. If senior creditors get to make decisions that primarily affect junior creditors, for example, then they are unlikely to take efficient decisions. An efficient reorganization plan that greatly benefits junior creditors but only slightly harms senior creditors is unlikely to get approved by the senior creditors.

Bankruptcy law struggles with the allocation of decision making authority. Chapter 11 reorganization plans affect many different parties, who often argue about the merits of the plan. The bankruptcy code prescribes a specific procedure for reorganization plan approval that requires several rounds of majority voting. ${ }^{118}$ The process works as follows. ${ }^{119}$ The debtor in a chapter 11 bankruptcy proposes a plan of reorganization. Different "classes" of creditors then vote on a plan, where a class is defined as a group of claimants with "substantially similar interests". ${ }^{120}$ For a class to approve a plan, a majority of individual creditors holding two thirds of the face value of debt within a class must approve the plan. If a class's claims are unimpaired by the plan-the class retains its pre-bankruptcy legal rights, then that class is deemed to have

\footnotetext{
${ }^{117}$ See Lucian A. Bebchuk, A New Approach to Corporate Reorganization, 101 Harv. L. Rev. 775 (1988); Yair Listokin, Paying for Performance in Bankruptcy: Why CEOs Should Be Compensated with Debt, 155 U. Pa. L. Rev. 777 (2007).

${ }^{118}$ See 11 U.S.C. Sec. 1129

${ }^{119}$ For a lucid description of plan approval, see Douglas Baird, The Elements of Bankruptcy Chapter 11 ( $4^{\text {th }}$ ed. 2006).

${ }^{120} 11$ U.S.C. $1122(a)$.
} 
approved the plan without voting. If a class vote rejects the plan, the court may still approve the plan if it can be shown that the dissenting class is paid in full. ${ }^{121}$

Majority voting's flaws explain many of the pitfalls of the reorganization process. Creditors must be grouped into classes because a single vote of all creditors on a plan combines the votes of creditors with extremely heterogeneous interests, leading to a likelihood of inefficient outcomes. This "solution" to heterogeneity is imperfect, as evidenced by the substantial amount of litigation concerning class construction. ${ }^{122}$ The dual voting requirements, a majority of the number of creditors within a class as well as $2 / 3$ of value, resembles a "majority of the minority" rule that prevents single large members of the class from pursuing plans that harm the minority members of the class. And even with all of these modifications of ordinary majority voting to prevent bad outcomes, section 1129(b), the cramdown provision, allows a judge to override the vote of a dissenting class and approve the plan.

The purpose of 1129(b), which allows a judge to approve a plan in spite of a class's rejection of the plan is to prevent hold up. A class of creditor's may be legally impaired, but get paid in full by a plan of reorganization that is efficient for the debtor as a whole. Nevertheless, the class that is legally but not practically impaired can seek to obtain greater than full compensation by "holding up" a plan of confirmation and demanding more compensation in exchange for approval. The cramdown provision limits a class's ability to do this by allowing a court to approve a reorganization in spite of a class's dissent. The cramdown provision thereby limits the extent to which creditor heterogeneity can restrict the formulation on an efficient plan of reorganization.

While the cramdown's ability to diminish the potential costs of creditor heterogeneity is appealing, the cramdown process is very expensive. ${ }^{123}$ Because valuations in bankruptcy are opaque, ${ }^{124}$ many classes can claim that they have not been paid in full by the plan, barring a cramdown. Still other classes will dispute these claims, providing alternative valuations demonstrating that the dissenting class's are paid in full. Instead of providing a clear procedure for plan approval via majority voting, the cramdown procedure enables approval to depend on arcane debates about the merits of various valuation techniques.

The voting process is also subject to heterogeneity in the form of empty voting, whereby creditors vote their interests in a class not to maximize the value of the class, but rather to exploit the majority voting control mechanism to maximize other interests. As a recent survey notes, "during the bankruptcy proceeding and because of its control position as a creditor, [a creditor] may use several tactics to delay and frustrate the Chapter 11 process." 125 In total, the complexity of the plan of reorganization approval process, and its continued susceptibility to manipulation, stems directly from the difficulty of aggregating extremely diverse classes of claims via majority voting. ${ }^{126}$

\footnotetext{
${ }^{121} 11$ U.S.C. 1129(b). Someone can be legally impaired but still paid in full. For example, if debt with a face value of $\$ 100$ is exchanged for equity with a value of $\$ 100$, then a creditor is paid in full, but their claim has been legally impaired.

${ }^{122}$ See Douglas Baird, The Elements of Bankruptcy 257-62 (4 $4^{\text {th }}$ ed. 2006).

123 Baird, at 251.

${ }^{124}$ Baird, at 251.

1252008 Colum. Bus. L. Rev. 610, 620 (.2008).

${ }^{126}$ Recognizing this, scholars have proposed a number of procedures to produce efficient plans without the messiness of chapter 11 approval voting. See, e.g., Bebchuk, supra note 117; Aghion, Hart \& Moore, The
} 
The pivotal mechanism offers a relatively simple alternative to the complexity of Chapter 11 plan approval process. Instead of multiple layers of majority voting, there should be one round of the pivotal mechanism, with all stakeholders in the bankrupt company participating. One plan of reorganization or a set of plans may be presented to the stakeholders. ${ }^{127}$ The plan that receives the highest value via the pivotal mechanism becomes the plan that is approved. As demonstrated above, the truth telling aspects of the mechanism and the mechanism's ability to accommodate heterogeneity insure that the plan that is approved is the most efficient for the entire group of stakeholders. In one round, the pivotal mechanism thus produces a better outcome than the current chapter 11 approval process does through multiple overlapping rounds.

Not surprisingly, the pivotal mechanism requires some modification in order to function effectively in the bankruptcy context. An approved plan may be efficient, but it does not necessarily adhere to the absolute priority rule requiring senior creditors to be paid in full before junior creditors receive value. To preserve the absolute priority rule, any plan presented to the voters could require senior creditors to receive cash equal to the face value of their claims or otherwise pass a "paid in full" test. ${ }^{128}$

Collusion will also be a complication for the pivotal mechanism's operation. If a stakeholder can participate multiple times, it could "collude "with itself, preventing the mechanism from yielding efficient outcomes. Rules would have to be established limiting the right of two entities under common control from participating. Other rules would have to limit the ability of one stakeholder to collude with others, though the inherent instability of such voting cartels limits the risk from this form of collusion.

If rules cannot prevent multiple participation, a majority voting pivotal mechanism hybrid may be effective. Creditors will be divided into classes with similar claims, much like current bankruptcy procedure and will elect representatives by majority vote. The representatives will then participate in the pivotal mechanism. This combination limits collusion (because the goals of each representative will be very different) relative to the pivotal mechanism alone. The hybrid plan also raises the probability that the plan that is approved is efficient relative to the existing chapter 11 plan approval mechanism. Unfortunately, the hybrid plan reintroduces some of the complications — such as defining classes - that are avoided by implementing the pivotal mechanism alone. As a result, the hybrid plan is only desirable if the costs of collusion prove large.

\section{Other Applications of the Pivotal Mechanism}

Small firm and bankruptcy decision making demonstrate two areas where the pivotal mechanism appears particularly attractive because the costs of heterogeneity are

Economics of Bankruptcy Reform, 8 J.L. Econ. \& Org. 523 (1992); Barry E. Adler \& Ian Ayres, A Dilution Mechanism for Valuing Corporations in Bankruptcy, 111 Yale L.J. 83, 85 (2001). All the plans are extremely complex, and none have been adopted.

${ }^{127}$ At present, a chapter 11 debtor enjoys a time limited exclusive right to propose a plan of reorganization. See Michelle M. Harner, The Corporate Governance and Public Policy Implications of Activist Distressed Debt Investing, 77 Fordham L. Rev. 703, 750-752 (2008). This provision is much debated, but majority voting requires a limit on the number of reorganization plans in order to prevent cycling and other inefficiencies associated with voting. By allowing efficient consideration of multiple plans at once, the pivotal mechanism could moot the debate over who should have the right to offer a plan of reorganization. ${ }^{128}$ See In re Integrated Telecom Express, Inc., 384 F.3d 108, 118, cert. denied, 125 S. Ct. 2542 (U.S. 2005). 
large while the costs of implementing the pivotal mechanism appear manageable. The pivotal mechanism offers benefits whenever decisions affect a heterogeneous group of stakeholders, some of whom are unable to participate in control in the majority voting context. This section provides a speculative look at two additional representative applications of the mechanism. The costs of the pivotal mechanism in these contexts, however, may well outweigh the benefits.

\section{Publicly Traded Corporations}

Publicly traded corporations have many stakeholders that are subject to shareholder expropriation because the other stakeholders do not exercise control. Creditors of the firm, for example, are subject to risk shifting where a corporation takes inefficiently high risks because the controlling shareholders enjoy all the upside but share the downside with the creditors. Similarly, employees with outside options that are significantly worse than their current employment (this could arise because of efficiency wages ${ }^{129}$ or implicit contracts ${ }^{130}$ ), bear some of the costs of layoffs, but shareholders do not internalize these costs when making employment decisions.

The pivotal mechanism could ameliorate these inefficiencies by allowing creditors and employees to participate in the mechanism. By enabling all parties affected by a decision to participate in the decision, the pivotal mechanism reduces the risk of inefficient decisions. Moreover, the heterogeneity introduced by allowing such disparate stakeholders to participate does not undermine the pivotal mechanism's ability to produce efficient outcomes.

The pivotal mechanism's benefits, however, will be lower than they are in bankruptcy. Risk shifting is only a problem for companies that have inadequate equity. Similarly, employees with jobs much better than outside options are often protected by unions (think of autoworkers). Thus, in most situations shareholders truly are primarily residual claimants, reducing the benefits of accommodating heterogeneity through the pivotal mechanism.

The pivotal mechanism also has high costs in public companies. Policing participants to prevent collusion is extremely difficult when there are millions of shareholder and other stakeholders, as may be the case with public companies. ${ }^{131}$ In addition, claimants to residual profits have few contractual protections. Because they do not work for the firm, they also suffer from principal agent problems. Voting control may therefore be the only factor that makes a claim on residual profits feasible. By diffusing residual claimant control, the pivotal mechanism may make a residual claim untenable.

Because the benefits of the pivotal mechanism are relatively small but the costs are large, public corporations are not likely to benefit from adopting the mechanism.

\footnotetext{
${ }^{129}$ Alan B. Krueger \& Lawrence H. Summers, Efficiency Wages and the Inter-Industry Wage Structure, 56 Econometrica 259 (1988).

${ }^{130}$ Paul Beaudry \& John DiNardo, The Effect of Implicit Contracts on the Movement of Wages Over the Business Cycle: Evidence from Micro Data, 99 J. Pol. Econ. 665 (1991).

${ }^{131}$ If the benefits of heterogeneous preference aggregation are sufficiently high, collusion could be mitigated by creating classes of similar stakeholders and have representatives of the classes participate in a majority vote, as described in the preceding subsection with respect to bankruptcy.
} 


\section{Non Profit Organizations}

The pivotal mechanism may also provide governance assets to charitable organizations. In many such organizations, management is self perpetuating and exercises complete control over the organization. This raises the obvious potential for agency problems. Any agency problem that cannot be solved by contract or reputation becomes an acute problem for the organization, which has no other source of controlling stakeholders to monitor the agents. As discussed in Part II, non profit organizations with management in complete control should only arise when heterogeneity problems prevent any other group from exercising effective control.

For example, large donors with intense preferences may be reluctant to share control with other smaller donors if each donor is given one vote. Instead, large donors may prefer management control, in spite of the agency problems. But if the cost of heterogeneity can be mitigated, however, then control may be expanded to include donors. The pivotal mechanism provides one method of aggregating donor preferences while accounting for preference intensity. It may therefore provide an additional option for non profit governance.

The benefits of the mechanism should not be overstated, however. Donors already enjoy considerable informal control over a non profit organization. By withholding donations, donors can insure that they do not contribute to a poorly governed organization. Moreover, introducing such formal pecuniary control over a non profit may dilute the nonpecuniary motives that are particularly important for the effective functioning of a non profit organization. ${ }^{132}$

\section{Conclusion}

As the applications just presented indicate, it is not clear whether the benefits of the pivotal mechanism in terms of efficient decision making will outweigh the costs for any organization. As a result, it is important to reemphasize that the mechanism should be enacted as a menu option, and not as a requirement. The most important benefit of the pivotal mechanism is that it aggregates diverse preferences in an efficient way. The mechanism will therefore be most attractive in contexts where control must be shared by a diverse set of individuals. As a result, enacting the pivotal mechanism as a menu option for collective choice will significantly expand the set of choices of organizational form and decision making for organizations beset with significant preference heterogeneity among stakeholders. The creation of such public goods is the primary purpose of organizational law. ${ }^{133}$

\footnotetext{
${ }^{132}$ Ernst Fehr \& Armin Falk, Psychological Foundations of Incentives, 46 Euro. Econ. Rev. 687, 689-704 (2002) (explaining that nonpecuniary motives influence behavior).

133 See Frank Easterbrook \& Daniel Fischel, The Corporate Contract, 89 Columbia Law Review 1416 (1989).
} 
